\title{
Identified Serotonergic Modulatory Neurons Have Heterogeneous Synaptic Connectivity within the Olfactory System of Drosophila
}

\author{
[Daylynn E. Coates, ${ }^{1}$ Adam T. Majot, ${ }^{1}$ Xiaonan Zhang, ${ }^{2}$ Cole T. Michael, ${ }^{1}$ Stacy L. Spitzer, ${ }^{1}{ }^{\complement}$ Quentin Gaudry, ${ }^{2}$ \\ and Andrew M. Dacks ${ }^{1}$ \\ ${ }^{1}$ Department of Biology, West Virginia University, Morgantown, West Virginia 26506, and 2Department of Biology, University of Maryland, College Park, \\ Maryland 20742
}

Modulatory neurons project widely throughout the brain, dynamically altering network processing based on an animal's physiological state. The connectivity of individual modulatory neurons can be complex, as they often receive input from a variety of sources and are diverse in their physiology, structure, and gene expression profiles. To establish basic principles about the connectivity of individual modulatory neurons, we examined a pair of identified neurons, the "contralaterally projecting, serotonin-immunoreactive deutocerebral neurons" (CSDns), within the olfactory system of Drosophila. Specifically, we determined the neuronal classes providing synaptic input to the CSDns within the antennal lobe (AL), an olfactory network targeted by the CSDns, and the degree to which CSDn active zones are uniformly distributed across the AL. Using anatomical techniques, we found that the CSDns received glomerulus-specific input from olfactory receptor neurons (ORNs) and projection neurons (PNs), and networkwide input from local interneurons (LNs). Furthermore, we quantified the number of CSDn active zones in each glomerulus and found that CSDn output is not uniform, but rather heterogeneous, across glomeruli and stereotyped from animal to animal. Finally, we demonstrate that the CSDns synapse broadly onto LNs and PNs throughout the AL but do not synapse upon ORNs. Our results demonstrate that modulatory neurons do not necessarily provide purely top-down input but rather receive neuron class-specific input from the networks that they target, and that even a two cell modulatory network has highly heterogeneous, yet stereotyped, pattern of connectivity.

Key words: connectivitiy; Drosophila; heterogeneity; neuromodulation; serotonin

Significance Statement

Modulatory neurons often project broadly throughout the brain to alter processing based on physiological state. However, the connectivity of individual modulatory neurons to their target networks is not well understood, as modulatory neuron populations are heterogeneous in their physiology, morphology, and gene expression. In this study, we use a pair of identified serotonergic neurons within the Drosophila olfactory system as a model to establish a framework for modulatory neuron connectivity. We demonstrate that individual modulatory neurons can integrate neuron class-specific input from their target network, which is often nonreciprocal. Additionally, modulatory neuron output can be stereotyped, yet nonuniform, across network regions. Our results provide new insight into the synaptic relationships that underlie network function of modulatory neurons.

\section{Introduction}

Neural networks alter the manner in which they process information based on the current physiological state of the animal.

Received Jan. 21, 2017; revised May 20, 2017; accepted June 19, 2017.

Author contributions: K.E.C., C.T.M., Q.G., and A.M.D. designed research; K.E.C., A.T.M., X.Z., C.T.M., S.L.S., Q.G., and A.M.D. performed research; K.E.C., A.T.M., X.Z., C.T.M.,S.L.S., Q.G., and A.M.D. analyzed data; K.E.C., A.T.M., X.Z., C.T.M., S.L.S., Q.G., and A.M.D. wrote the paper.

This work was supported by National Institutes of Health Grant 1 R03 DC013997-01, West Virginia University Senate Research and Scholarship Grant Award R-16-036, and West Virginia University start-up funds to A.M.D., West Virginia University Center for Neuroscience Summer Undergraduate Research Internships NIGMS 5 P30 GM103503 to S.L.S. and C.T.M., and a Whitehall Fellowship to Q.G. We thank Dr. Tzumin Lee, Dr. Tim Mosca, Dr. Gerry Rubin, and
This can be achieved via modulatory nuclei, or even individual modulatory neurons, that project broadly throughout the brain to alter dynamics of specific networks (Hurley et al., 2004). These nuclei receive synaptic input from a diverse array of sources;

Dr. Jing Wang for generous contributions of fly lines; and Ayad Auda, Kristyn Lizbinski, Tyler Sizemore, and Dr. Kevin Daly for helpful comments on the manuscript.

The authors declare no competing financial interests.

Correspondence should be addressed to Dr. Andrew M. Dacks, West Virginia University, Life Sciences Building, Biology, 53 Campus Drive, Morgantown, WV 26506. E-mail: andrew.dacks@mail.wvu.edu.

https://doi.org/10.1523/JNEUROSCI.0192-17.2017

Copyright $\odot 2017$ the authors $\quad 0270-6474 / 17 / 377318-14 \$ 15.00 / 0$ 
consequently, the neural mechanisms controlling modulatory nuclei are often complex. For example, the synaptic inputs to serotonergic raphe neurons include cortex, striatum, midbrain, and hypothalamus (Ogawa et al., 2014; Pollak Dorocic et al., 2014; Weissbourd et al., 2014) and raphe neurons modulate activity in a wide array of networks, including those regulating sensory functions (Hurley et al., 2004; Petzold et al., 2009; Kapoor et al., 2016; Lottem et al., 2016), reward (Nakamura, 2013), and emotional states (Hale et al., 2012). Likewise, there is increasing evidence that modulatory nuclei can also receive input from their target network (Sim and Joseph, 1993; Peyron et al., 1996; Pollak Dorocic et al., 2014), suggesting that the synaptic relationships between modulatory nuclei and their targets are to some extent reciprocal. Numerous studies have suggested that even a subpopulation of neurons within a given modulatory nucleus are diverse in terms of their genetic lineages, physiological characteristics, morphology, and functionality (O'Hearn and Molliver, 1984; Jensen et al., 2008; Wylie et al., 2010; Bang et al., 2012; Andrade and Haj-Dahmane, 2013; Okaty et al., 2015). However, the extent to which individual modulatory neurons have reciprocal synaptic relationships or provide uniform synaptic output within a target network is unclear, as is the degree to which features of modulatory neuron synaptic connectivity are stereotyped from animal to animal.

Identified modulatory neurons provide a framework for studying heterogeneity of synaptic relationships across a target network (i.e., is a given relationship maintained across a network) and the degree to which observed heterogeneity is stereotyped (i.e., is connectivity variable across individuals). The Drosophila olfactory system is innervated by a single pair of serotonergic modulatory neurons, the "contralaterally projecting, serotoninimmunoreactive deutocerebral neurons" (CSDns) (Dacks et al., 2006; Roy et al., 2007; Zhang and Gaudry, 2016) and the principal AL neuron classes have been characterized extensively in terms of their response profiles, morphology, physiological characteristics, and transmitter content (Wilson, 2013). Thus, the CSDns represent an excellent model system to establish basic principles for connectivity of individual modulatory neurons as they are easily identified across animals and project to many synaptic layers within the olfactory system.

The CSDns are 2 of the $\sim 90$ serotonergic neurons in the central Drosophila brain (Vallés and White, 1988; Alekseyenko et al., 2010; Sitaraman et al., 2012; Pech et al., 2013; Pooryasin and Fiala, 2015). The CSDns project broadly throughout the olfactory system of Drosophila, innervating the antennal lobe (AL; the firstorder olfactory neuropil), lateral horn (LH) and mushroom body calyx (second-order olfactory neuropil), and superior lateral protocerebrum (a third-order processing region) (Dacks et al., 2006; Roy et al., 2007; Berck et al., 2016) and are conserved across many insect taxa (Kent et al., 1987; Dacks et al., 2006). The CSDns are the sole source of 5-HT innervation in the ALs and exogenous application of 5-HT (Kloppenburg and Hildebrand, 1995; Kloppenburg et al., 1999; Hill et al., 2003; Dacks et al., 2009; Zhang and Gaudry, 2016) as well as optogenetic activation of the CSDns (Zhang and Gaudry, 2016) modulate both local interneurons (LNs) and projection neurons (PNs). However, the synaptic relationships of the adult CSDns with principal AL neuron types are not known. Therefore, we sought to determine which AL neuron classes provide input to the CSDns and whether the CSDns synapse reciprocally with these neurons. We further asked whether this input was networkwide or glomerular-specific and whether it was stereotyped from animal to animal. Finally, we asked whether the CSDns' synaptic output was uniform across odor processing
Table 1. Antibodies used for immunocytochemistry

\begin{tabular}{|c|c|c|c|}
\hline Antigen & Species, manufacturer, catalog \# & Dilution & $\begin{array}{l}\text { Incubation } \\
\text { time }\end{array}$ \\
\hline $5-\mathrm{HT}$ & Goat (ImmunoStar, catalog \#20079, RRID:AB_572262) & 1:5000 & $24 \mathrm{~h}$ \\
\hline $5-\mathrm{HT}$ & Rabbit (ImmunoStar, catalog \#20080, RRID:AB_572263) & $1: 5000$ & $24 \mathrm{~h}$ \\
\hline Brp & Mouse (DSHB, catalog \#nc82, RRID:AB_2314868) & $1: 50$ & $5 d$ \\
\hline DsRed & $\begin{array}{l}\text { Rabbit (Clontech Laboratories, catalog \#632496, } \\
\text { RRID:AB_10013483) }\end{array}$ & $1: 250$ & $48 \mathrm{~h}$ \\
\hline $\begin{array}{l}\text { GFP (for } \\
\text { GRASP) }\end{array}$ & Mouse (Sigma-Aldrich, catalog \#G6539, RRID:AB_259941) & $1: 100$ & $24 \mathrm{~h}$ \\
\hline GFP & $\begin{array}{l}\text { Rabbit (Molecular Probes, catalog \#A-11122, } \\
\text { RRID:AB_221569) }\end{array}$ & $1: 1000$ & $24 \mathrm{~h}$ \\
\hline GFP & Chicken (Abcam, catalog \#ab13970, RRID:AB_300798) & 1:1000 & $24 \mathrm{~h}$ \\
\hline $\mathrm{N}$-Cadherin & Rat (DSHB, catalog \#DN-Ex \#8 RRID:AB_2619582) & 1:10 & $48 \mathrm{~h}$ \\
\hline
\end{tabular}

units (glomeruli) in the AL. Our results demonstrate that individual modulatory neurons integrate neuron class-specific input from their target networks and that even a two-cell modulatory network has heterogeneous, yet stereotyped synaptic connectivity.

\section{Materials and Methods}

Fly stocks. Flies were raised on standard cornmeal/agar/yeast medium at $25^{\circ} \mathrm{C}$ and $60 \%$ humidity on a $12: 12$ light/dark cycle. The following fly stocks were used in this study: MB465C split-Gal4 (Aso et al., 2014), R60F02-Gal4 (BDSC \#48228), UAS-GFP (BDSC \#32185), UAS-RFP, LexAop-GFP (BDSC \#32229), R10G02-LexA (BDSC \#61509), Or83bLexA::VP16 (Lai and Lee, 2006), LexAop-GFP (BDSC \#32207), LexAop$n s y b$-spGFP ${ }_{1-10}$, UAS-CD4-spGFP ${ }_{11}$ (BDSC \#64315), R32F10-LexA (BDSC \#61509), VGlut-LexA (Diao et al., 2015), GH146-LexA::GAD (Lai et al., 2008), R44A08-LexA (BDSC \#54863), Mz19-QF (BDSC \#41573), QUASChR2 (BDSC \#52260), UAS-syt.eGFP (BDSC \#6926), UAS-DTI (BDSC

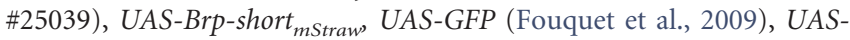
$n s y b$-spGFP ${ }_{1-10}$, and LexAop-CD4-spGFP ${ }_{11}$ (BDSC \#64314). Throughout this study, we use two different drivers, R60F02-Gal4 (Jenett et al., 2012) and MB465c-split Gal4 (Pfeiffer et al., 2010; Aso et al., 2014), which express selectively or exclusively, respectively, in both CSDns. The split Gal4 is an intersectional strategy that is used to restrict Gal4 expression to a single population of neurons (Luan et al., 2006; Pfeiffer et al., 2010; Aso et al., 2014), as Gal4 drivers rarely express in a single pair of neurons. R60F02 was not used to generate the MB465c split Gal4 line (which derives from R37D04-Gal4 and R51B02-Gal4); thus, the R60F02 Gal4 and MB465c split Gal4 fly lines give us independent means to examine the CSDns. All $\mathrm{R}_{\mathrm{x}}$ lines (e.g., R60F02) were originally generated in the lab of Dr. Gerry Rubin (Jenett et al., 2012).

Immunocytochemistry. Brains of approximately equal numbers of male and female flies were dissected in Drosophila external saline (Zhang et al., 2010): $135 \mathrm{~mm} \mathrm{NaCl}, 5 \mathrm{~mm} \mathrm{KCl}, 4 \mathrm{~mm} \mathrm{MgCl}_{2} \cdot 6 \mathrm{H}_{2} \mathrm{O}, 2 \mathrm{~mm}$ $\mathrm{CaCl}_{2} \cdot 2 \mathrm{H}_{2} \mathrm{O}, 5 \mathrm{~mm} \mathrm{~N}$-tris[hydroxymethyl]methyl-2-aminoethane sulfonic acid, $36 \mathrm{~mm}$ sucrose, $\mathrm{pH}$ 7.15, and fixed in 4\% PFA for $30 \mathrm{~min}$ at $4^{\circ} \mathrm{C}$. Brains were then washed in PBST (PBS with $0.5 \%$ Triton X-100) and blocked for $1 \mathrm{~h}$ in $2 \%$ BSA (Jackson ImmunoResearch Laboratories; \#001-000-162) in PBST, with the exception of syb:GRASP protocols, which used 4\% BSA. Brains were then incubated in primary antibodies diluted in block solution with $5 \mathrm{~mm}$ sodium azide. Dilutions and incubation times of primary antibodies are listed in Table 1. After incubation, brains were washed in PBST and blocked for $1 \mathrm{~h}$ in BSA. Secondary antibodies were then applied for $24 \mathrm{~h}$, except for protocols using the Brp (Wagh et al., 2006) or N-cadherin (Iwai et al., 1997) antibodies, which had a $48 \mathrm{~h}$ incubation period. Brains were then washed in PBST and PBS, run through an ascending glycerol series (40\%,60\%, and $80 \%)$, and mounted in VectaShield (Vector Labs H-1000). Images were acquired using either a $40 \times$ or $60 \times$ oil-immersion lens on an Olympus FV1000 confocal microscope. Image processing occurred in Olympus Fluoview FV10-ASW (RRID:SCR_014215), VAA3D (RRID:SCR_002609), and FIJI (RRID:SCR_002285). Images were stitched together using Photoshop (RRID:SCR_014199) as needed. All figures were organized using CorelDraw X4 (RRID:SCR_014235). With the exception of Figure 1C, all 
images depict a "frontal" orientation in which the medial to lateral and dorsal to ventral axes are visible. To determine the number of glomeruli innervated by GH146-LexA::GAD PNs, we used GFP expression and Brp-ir.

syb:GRASP immunocytochemistry. Induction of syb:GRASP was performed using $\mathrm{KCl}$ washes as previously described (Macpherson et al., 2015). Briefly, brains were rinsed alternating between $70 \mathrm{~mm} \mathrm{KCl}$ and Drosophila external saline, $3 \times$ for $5 \mathrm{~s}$ per wash type. Brains were then incubated for $10 \mathrm{~min}$ in Drosophila external saline at room temperature. Immunocytochemistry was then performed as described above. A mouse monoclonal antibody was used to label the reconstituted GFP (Gordon and Scott, 2009); therefore, neuropils were marked using a rat N-cadherin antibody (Iwai et al., 1997) rather than the mouse Brp antibody (Wagh et al., 2006), which is a commonly used neuropil label. The location of GFP reconstitution within the AL was extremely consistent. However, for some syb:GRASP combinations, GFP reconstitution was observed in only a proportion of animals; and in the remaining animals, no GFP reconstitution was visible anywhere in the brain. The proportions of animals expressing GFP reconstitution for each driver combination are noted in Results. It should be noted that different fly line combinations in syb:GRASP experiments differ in the sparseness of the GFP reconstitution due to number of neurons expressed in each line (and therefore total number of potential synaptic connections) and strength of driver. In the syb:GRASP experiments, colabeling for 5-HT was used to confirm that the reconstituted GFP occurs only on the surface of the CSDn processes.

Brp-Short puncta counts. To mark individual active zones of the CSDns, we used Brp-short ${ }_{\text {mstraw }}$ (Mosca and Luo, 2014) which is a nonfunctional, fluorescently tagged form of the active zone protein Bruchpilot (Brp) (Wagh et al., 2006). Brp-short has been extensively validated as a marker of active zones using immunoelectron microscopy and association with other active zone markers (Schmid et al., 2008; Fouquet et al., 2009; Owald et al., 2010; Mosca and Luo, 2014), and has been previously used to quantify active zones in the Drosophila antennal lobes (Mosca and Luo, 2014), mushroom body (Kremer et al., 2010; Christiansen et al., 2011), and optic lobes (Berger-Müller et al., 2013).

We simultaneously expressed UAS-Brp- short $_{\text {mStraw }}$ and UAS-GFP in the CSDns using MB465c-spGal4. Confocal optical stacks of Brp-short expression in the CSDns were adjusted for contrast in FIJI and exported as Tiff file stacks for manual marking of individual puncta in VAA3D (Peng et al., 2010). Each glomerulus was identified, and individual Brpshort puncta were localized across two $2 \mathrm{D}$ planes and quantified $(n=$ 7-12 per glomerulus). All marker placements were verified by two observers and compared with UAS-GFP expression to confirm that puncta were associated with CSDn branches. Glomeruli that could not be reliably identified across animals were excluded. The volume of each identified glomerulus was determined using the FIJI add-on volumes (Merzin, 2008), and volumes were averaged across samples. To calculate the puncta density for each glomerulus, average puncta counts for each glomerulus were divided by glomerular volume. Average density values were then normalized across all glomeruli, and these values were assigned gradation values of the color red for each glomerulus to generate the heat map in Figure 6D1-D3. Gray glomeruli are those that could not be identified with confidence across preparations.

Electrophysiology and optogenetic stimulation. Whole-cell recordings were performed as previously described by Zhang and Gaudry (2016). Data were low-pass filtered at $5 \mathrm{kHz}$ using a model 2400 amplifier (AM Systems) and digitized at $10 \mathrm{kHz}$. Pipettes were pulled from thin-walled borosilicate glass (World Precision Instruments; $1.5 \mathrm{~mm}$ outer diameter, $1.12 \mathrm{~mm}$ inner diameter) to a resistance of $8-12 \mathrm{M} \Omega$. Neurons were visualized using oblique illumination from an infrared LED guide through a fiber optic (Thorlabs) (Maimon et al., 2010). The external recording solution contained the following (in $\mathrm{mm}$ ): $103 \mathrm{NaCl}, 3 \mathrm{KCl}$, $5 \mathrm{~N}$-tris(hydroxymethyl)methyl-2-aminoethane-sulfonic acid, 8 trehalose, 10 glucose, $26 \mathrm{NaHCO}_{3}, 1 \mathrm{NaH}_{2} \mathrm{PO}_{4}, 1.5 \mathrm{CaCl}_{2}$, and $4 \mathrm{MgCl}_{2}$ (adjusted to $270-275 \mathrm{mOsm}$ ). The saline was bubbled with $95 \% \mathrm{O}_{2} / 5 \% \mathrm{CO}_{2}$ and reached a $\mathrm{pH}$ of 7.3. Our internal solution contained in mM: 140 potassium aspartate, $10 \mathrm{HEPES}, 4 \mathrm{MgATP}, 0.5 \mathrm{Na}_{3} \mathrm{GTP}, 1$ EGTA, and 1 $\mathrm{KCl}$. A small hyperpolarizing current was applied to offset the depolarization caused by the pipette seal conductance. Their resting potentials were adjusted slightly to match the firing rate of similar neurons obtained in cell-attached recordings. Neurons that did not fire spontaneously or that had depolarized membrane potentials upon break-in were excluded from the study. For optogenetic stimulation, we used a high-powered Blue LED (Thorlabs M470L3, $470 \mathrm{~nm}$ ) to stimulate channelrhodopsin-2 expressing neurons. The LED was mounted into the epifluorescence light path and light was presented at $0.057 \mathrm{~mW} / \mathrm{mm} 2$ as measured by a Thorlabs light meter PM100A with light sensor S130C. Flies expressing channelrhodopsin-2 were raised on food containing $0.2 \mathrm{~mm}$ all-transretinal. $\mathrm{mm}$ all-trans-retinal. All-trans retinal was prepared as a stock solution in ethanol $(35 \mathrm{~mm})$, and $28 \mu \mathrm{l}$ of this stock was mixed into $\sim 5 \mathrm{ml}$ of rehydrated potato flakes and added to the top of a vial of conventional food.

Statistics. Graph Pad Prism version 6.01 (GraphPad Software, RRID: SCR_002798) was used for all statistical analyses. A two-way paired $t$ test was used for physiological data analysis. A D'Agostino-Pearson omnibus normality test was used to determine normality of the puncta count data, and a Kruskal-Wallis was used to determine whether active zone density varied across glomeruli in Figure 6E. Coefficient of Variance was calculated for each glomerulus (see Fig. $6 F$ ) to measure the degree of variability of puncta counts.

\section{Results}

Whereas the connectivity of principal AL neurons has been established in Drosophila, the synaptic connectivity of the CSDns with principal AL neurons are not well known. Therefore, we sought to determine which principal AL neurons synapse with the CSDns in the AL and characterize the reciprocity of their synaptic relationships. We then asked whether the CSDns synaptic output was uniform across glomeruli in the $\mathrm{AL}$ and whether these connectivity relationships were stereotyped.

\section{Basic CSDn morphology}

The CSDns were first described in Manduca sexta (Kent et al., 1987) and were thereafter characterized in many holometabolous (complete metamorphosing) insects (Wegerhoff, 1999; Hill et al., 2002; Dacks et al., 2006; Roy et al., 2007), including Drosophila. In Drosophila, the CSDn soma reside in the lateral cell cluster of the AL on each side of the brain (Fig. 1). A few processes extend off the primary neurite into the coarse neuropil of the AL, whereas the primary process projects dorsoposteriorly along the medial AL tract (m-ALT) to innervate several ipsilateral and contralateral protocerebral regions, including the antler, mushroom body calyx, superior lateral protocerebrum, and LH (Ito et al., 2014). The CSDns projects anteroventrally along the contralateral $\mathrm{m}$-ALT to the contralateral AL where they branch extensively. Finally, the CSDns extends a small process across the antennal commissure to sparsely innervate the ipsilateral AL (Dacks et al., 2006) (Fig. 1 A,B). The CSDns' axons branch within most, if not all, glomeruli in the AL, and their innervation varies in a glomerulus-specific manner (discussed below). The CSDns are serotonergic (Fig. 1C) and have also been reported to be cholinergic (Zhang and Gaudry, 2016).

\section{The CSDns receive glomerulus-specific excitatory input and antennal lobe-wide inhibitory input}

Anatomical evidence from larval and adult Drosophila (Roy et al., 2007; Berck et al., 2016; Zhang and Gaudry, 2016), as well as Manduca (Sun et al., 1993), indicate that the CSDns receive synaptic input within the AL. This suggests that ongoing network activity in the AL can affect the CSDns; however, the specific AL neuron classes that synapse upon the CSDns in adult Drosophila are unknown. There are three principal neuronal classes within the AL of Drosophila. Cholinergic ORNs on the antennae and maxillary palps that express a given chemoreceptive protein in- 

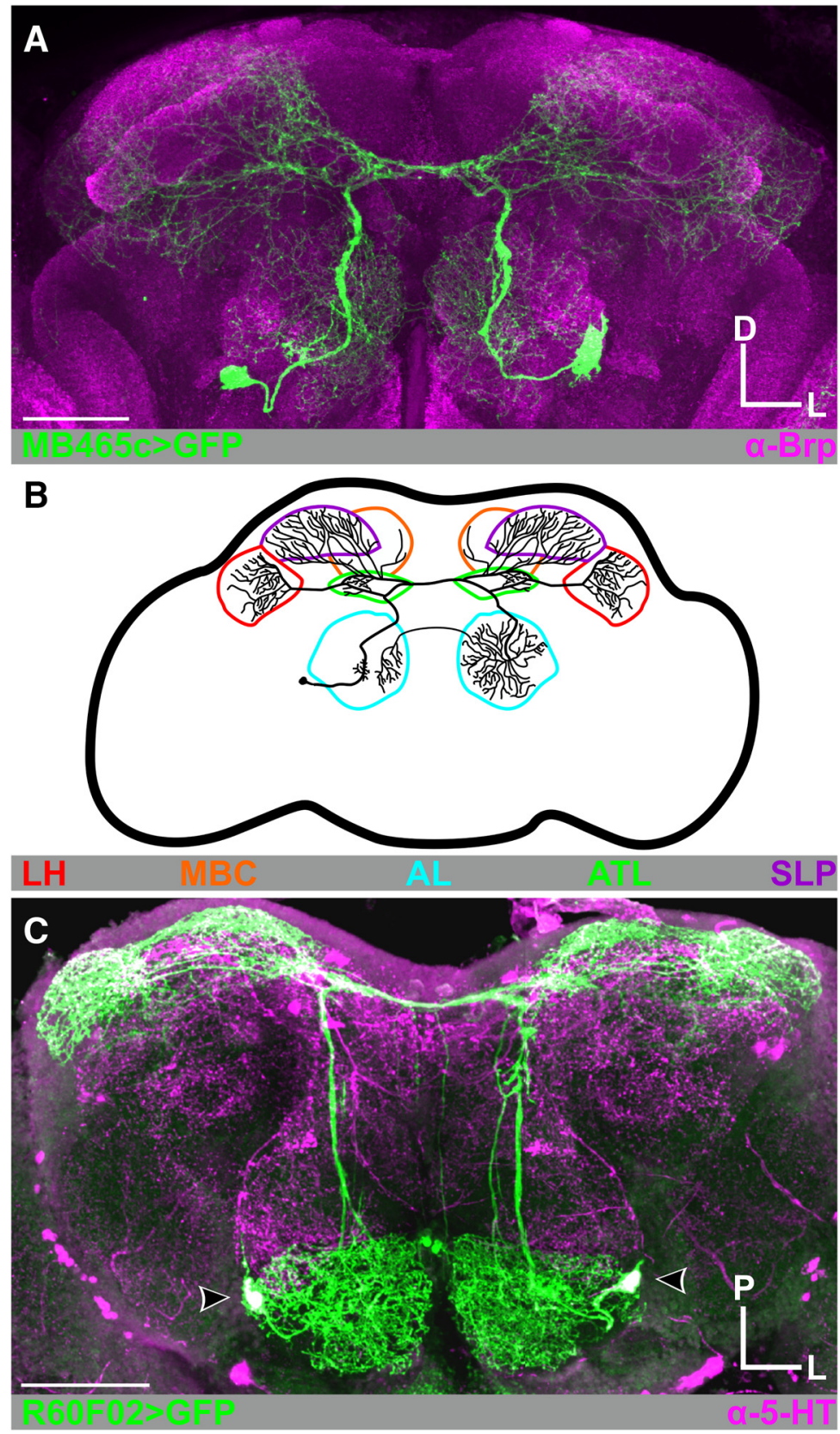

Figure 1. CSDn morphology. $A, M B 465 C$-spGal4-driven expression of GFP (green) highlights the broadly projecting innervation pattern of the CSDns throughout the Drosophila brain. Neuropils are delineated with Brp-ir in magenta. $\boldsymbol{B}$, Schematic of a single CSDn. The CSDns project throughout the olfactory system, including the antennal lobes (AL; cyan), antler (ATL; green), superior lateral protocerebrum (SLP; purple), mushroom body calyx (MBC; orange), and lateral horn (LH; red). In subsequent figures, diagrams represent specific regions of interest depicted in said figure. C, CSDns are 5-HT-immunoreactive (-ir). R60F02-Gal4-driven expression of GFP in the CSDns (green) completely overlaps with 5-HT-ir (magenta). Scale bars, $50 \mu \mathrm{m}$. D, Dorsal; L, lateral; $P$, posterior.

nervate the same AL glomerulus where they synapse upon GABAergic, cholinergic, and glutamatergic LNs, which refine olfactory signals, and PNs, which relay olfactory signals to the $\mathrm{LH}$ and mushroom body calyx (Martin et al., 2011; Wilson, 2013; Joseph and Carlson, 2015). The CSDns are responsive to exogenous application of acetylcholine, GABA, and glutamate (Zhang and Gaudry, 2016), indicating that all three principal AL neuron classes are potential presynaptic candidates. To identify the neuron classes that are presynaptic to the CSDns in adult Drosophila, we used a variant of GFP reconstitution across synaptic partners (GRASP) (Feinberg et al., 2008; Gordon and Scott, 2009). In this technique, partial GFP fragments are expressed extracellularly on the membrane by two neuron populations of interest. When the neurons come into contact, the GFP fragments at the site of contact reconstitute into a full GFP molecule, which can then be visualized using an antibody that only recognizes the full GFP molecule. For our experiments, we used synaptobrevin GRASP (syb:GRASP) in which one GFP fragment is fused to the presynaptic protein synaptobrevin (syb:spGFP ${ }_{1-10}$ ) and the other GFP fragment (CD4:spGFP $\left.{ }_{11}\right)$ is expressed extracellularly as described above (Macpherson et al., 2015). Thus, the presynaptic GFP fragment cannot reconstitute with the postsynaptic GFP fragment before vesicle fusion; consequently, GFP reconstitution is only induced at the synapse. This allows for screening of candidate AL neurons that are presynaptic to the CSDns at functional synapses in which we induced vesicle fusion using $\mathrm{KCl}$ washes (see Materials and Methods).

The CSDns are inhibited by most odors, and the strength of odor evoked inhibition increases with the strength of electroantennogram deflection (Zhang and Gaudry, 2016), which serves as a proxy for degree of network activation. This suggests that the CSDns receive a significant amount of synaptic input directly from LNs. R32F10-LexA is expressed in the AL only by $12.5 \pm 0.86$ LNs (SEM) (Fig. $2 A$; $n=8$ ), all of which are GABAergic (Fig. 2B). We drove expression of syb: GRASPspGFP $_{1-10}$ using R32F10-LexA and $\mathrm{CD}_{4}$ spGFP $_{11}$ in CSDns using MB465cspGal4. We observed syb:GRASP signal from the R32F10 LNs onto the CSDns throughout the AL (7 of 7 brains), spanning from anterior (Fig. 2C) to posterior depths (Fig. 2D). We next tested whether glutamatergic LNs are presynaptic to the CSDns because they likewise have overlapping innervation patterns (Fig. 2E). We drove expression of syb: GRASPspGFP $_{1-10}$ in glutamatergic LNs using VGlut-LexA (Diao et al., 2015) and, similar to GABAergic LNs, syb:GRASP signal was seen extensively throughout the AL (Fig. 2F; 8 of 9 brains).

Although the CSDns are primarily inhibited by odors, they are excited by ammonia and are responsive to exogenous application of acetylcholine (Zhang and Gaudry, 2016), suggesting that cholinergic ORNs and/or PNs may synapse upon the CSDns. To determine whether ORNs are presynaptic to the CSDns, we drove syb:GRASPspGFP ${ }_{1-10}$ in two LexA lines (Or83b-LexA and R10G02-LexA; Fig. $3 B$ and Fig. $3 D$, respectively, which are expressed by different populations of ORNs) and CD4-spGFP ${ }_{11}$ in the CSDns using MB465c-spGal4. Despite broad physical overlap of ORN and CSDn processes (Fig. $3 A, C$ ), we only identified syb: GRASP signal consistently in DL4 (Fig. 3B1; 12 of 12 brains), 

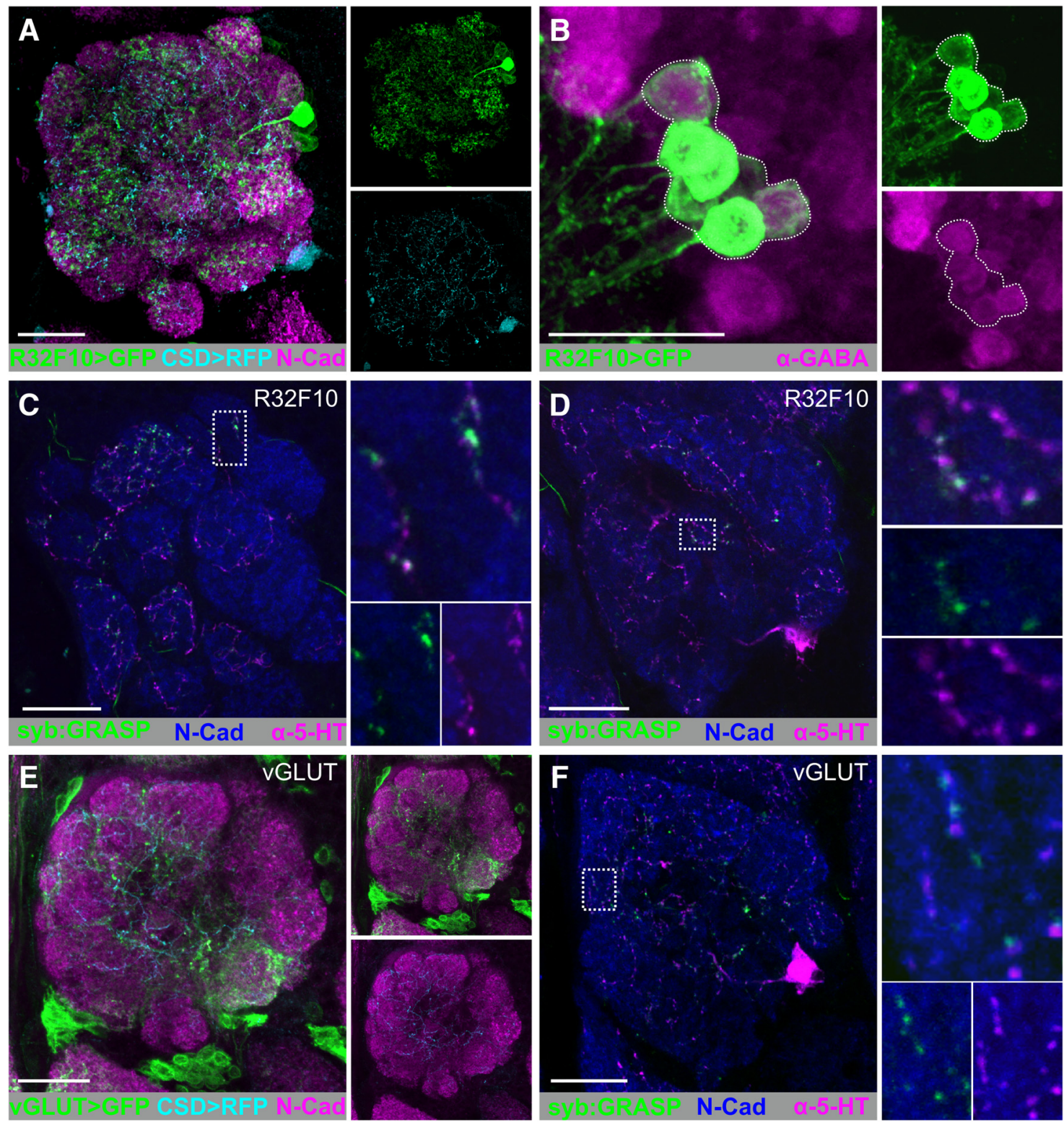

Figure 2. CSDns receive homogeneous input from GABAergic and glutamatergic LNs across the antennal lobe. $A$, RFP (cyan) expression by the CSDns (via MB465C-spGal4) and GFP (green) expression driven by a subset of LNs (via R32F10-LexA) in the AL. Brp-ir delineates neuropil (magenta). B, All LNs in R32F10-LexA are GABAergic. Representative confocal stack of seven R32F10-LexA cell bodies (GFP; green) colocalize with GABA-ir (magenta). C, D, syb:GRASP signal between R32F10-LexA (presynaptic) and MB465c-spGal4 (postsynaptic) in many glomeruli throughout the AL. C, Posterior depth. D, Anterior depth. E, RFP (cyan) expression by the CSDns (via R60F02-Gal4) and GFP (green) expression driven by glutamatergic LNs (via VGlut-LexA) in the AL.F, syb:GRASP signal between VGlut-LexA (presynaptic) and R60F02-Gal4 (postsynaptic) in many glomeruli throughout the AL. Reconstituted GFP (green) was identified as GFP-ir only in close association with 5-HT-ir processes (magenta). N-cadherin-ir delineates neuropil (blue). Scale bars, $20 \mu \mathrm{m}$.

DM2 (Fig. 3B2; 12 of 12 brains) and DM1 (Fig. 3B3; 12 of 12 brains) in Or83b-lexA brains, and VM1 (Fig. 3D1; 12 of 12 brains) in R10G02-LexA brains. In both lines, we observed additional glomeruli with syb:GRASP signal, which were not present across individuals as consistently as the glomeruli identified above. For instance, we observed syb:GRASP signal in the VA7l in 10 of 12 R10G02-LexA brains (Fig. 3D2). In Or83b-lexA brains, we also observed syb:GRASP signal in D (4 of 12 brains), VM2 (3 of 12 brains) DM3 ( 3 of 12 brains), DA2 (2 of 12 brains), DM4 ( 1 of 12 brains), DM5 (1 of 12 brains), and VM5v ( 1 of 12 brains). These results suggest that, although the connectivity of specific ORN populations onto the CSDns is consistent across individuals, there is also ORN-specific interanimal variability. Collectively, these results demonstrate that the CSDns receive input from ORNs in a glomerulus-specific manner.
Although PNs receive a large amount of input within the AL, $\mathrm{PN}$ processes have a significant amount of output synapses within a glomerulus (Kazama and Wilson, 2009; Rybak et al., 2016). Given the overlap of PN and the CSDn processes (Fig. 4A), we sought to determine whether cholinergic PNs are presynaptic to the CSDns. We therefore drove expression of syb:GRASPspGFP ${ }_{1-10}$ in GH146LexA::GAD and CD4-spGFP ${ }_{11}$ in the CSDns using MB465c-spGal4. GH146-LexA is expressed by cholinergic PNs predominantly from the lateral and anterodorsal cell clusters (Lai and Lee, 2006) in $~ 22$ glomeruli ( $n=4$ brains). Interestingly, syb:GRASP signal was seen only in the DM5 glomerulus (Fig. $4 B ; 10$ of 16 brains). We further confirmed that DM5 PNs synapse upon the CSDns using the R44A08-LexA, which, in the AL, is expressed by DM5 (Fig. $4 C$ ) and DL3 PNs (data not shown). Yet, GFP reconstitution was only present in DM5 (Fig. 4D; 7 of 9 brains). To determine the 

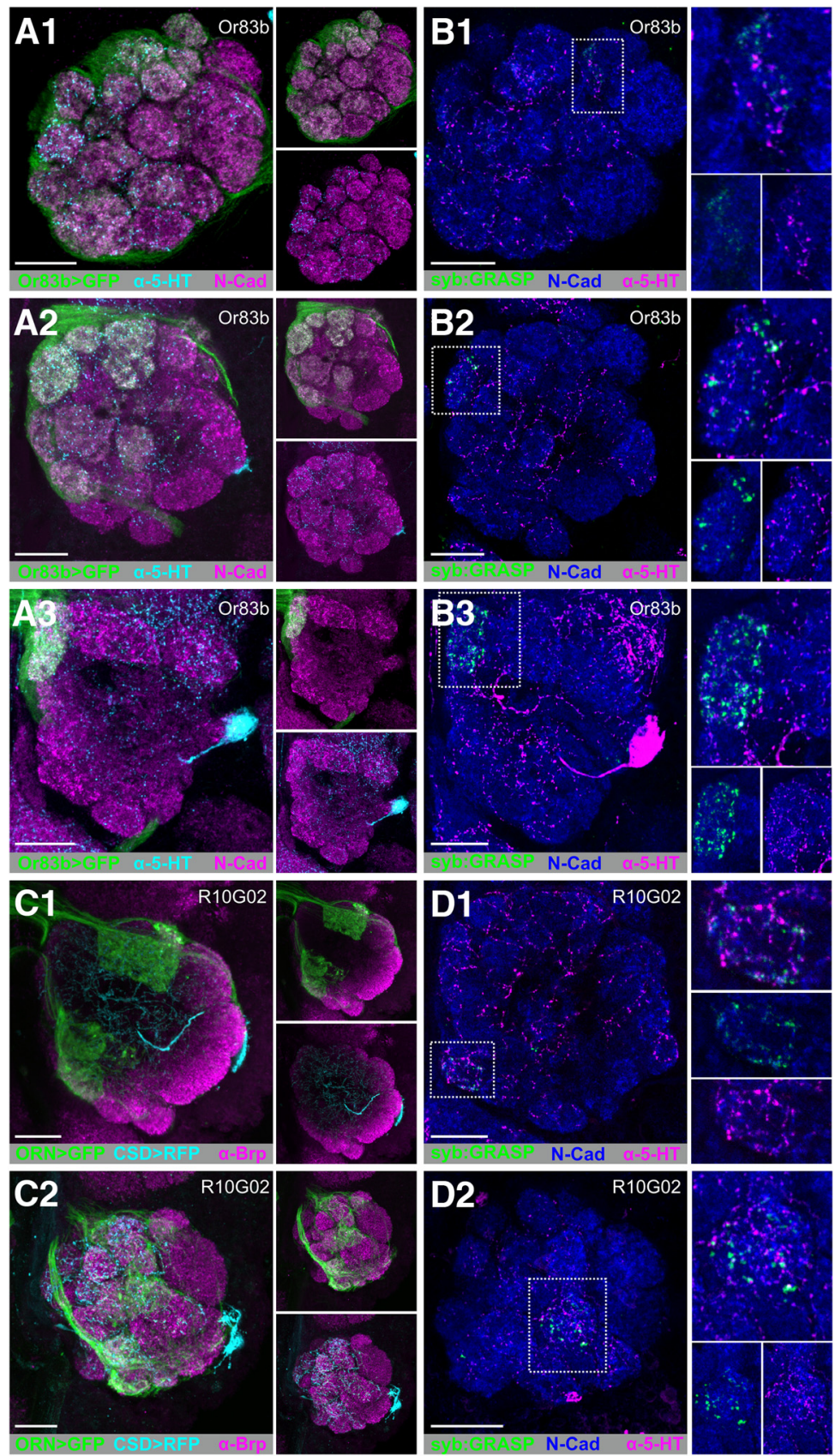

Figure 3. ORNs provide glomerulus-specific input to the CSDns in the AL. $A$, GFP-driven expression of Or83b-LexA (green) and 5HT-ir (cyan) in the AL at (A1) anterior, (A2) middle, and (A3) posterior depths. $\boldsymbol{B}$, syb:GRASP signal of Or83b-LexA (presynaptic) and MB465C-spGal4 (postsynaptic) is located within DL4, DM2, and DM1 as depicted by scans at (B1) anterior, (B2) middle, and (B3) posterior depths. C, RFP (cyan) expression by the CSDns (via MB465C-spGal4) and GFP (green) expression by a subset of ORNs (via R10G02-LexA) in the AL. R10G02 labels a subset of ORNs, including some that express IRs. C1, Anterior, C2, Posterior. $\mathrm{N}$-cadherin-ir delineates neuropil in $\boldsymbol{A}$ and $\boldsymbol{B}$. Brp-ir delineates neuropil in $\boldsymbol{C}$. $\boldsymbol{D}$, syb:GRASP signal between R10G02-LexA (presynaptic) and MB465c-spGal4 (postsynaptic) is localized to just two glomeruli: VM1 (C1) and VA7I (C2). N-cadherin-ir delineates neuropil (blue). Reconstituted GFP (green) was identified as GFP-ir only in close association with 5-HT-ir processes (magenta). $\mathrm{N}$-cadherin-ir delineates neuropil (blue) in D. syb:GRASP was observed less frequently in VA7l (B1) via R10G02 and DL4 (D2) via Or83b-LexA, suggesting interanimal variability. Scale bars, $20 \mu \mathrm{m}$.

extent to which a small number of PNs in a single glomerulus could affect the activity of the CSDns, we obtained whole-cell patchclamp recordings from the CSDns while activating PNs via Mz19-QF expression (Hong et al., 2012) of QUAS-ChR2. Photoinduced activation of PNs caused a fast EPSP in the CSDns that was blocked by subsequent application of the nicotinic acetylcholine receptor antagonist mecamylamine (Fig. $4 E, F ; n=7$ CSDns,

$p=0.0053$, paired $t$ test). Together, our results suggest that the CSDns receive excitatory input in a glomerulus-specific manner from both ORNs and PNs (Fig. $4 G)$ and networkwide inhibitory input from LNs (Fig. 2C, $D, F$ ) within the AL.

CSDns' synaptic output is broad, yet heterogeneous, throughout the $\mathrm{AL}$

Electron microscopy and transgenic studies have demonstrated that the CSDns have presynaptic terminals in the AL of Manduca sexta (Sun et al., 1993) and Drosophila (Roy et al., 2007; Zhang and Gaudry, 2016), respectively. However, localization of CSDn active zones throughout the rest of the olfactory system is largely unexplored. Therefore, we drove expression of synaptotagmin-GFP (syt.eGFP) (Zhang et al., 2002) in the CSDns; and consistent with these previous studies, syt.eGFP was found throughout the AL (Fig. 5A). We also observed syt.eGFP expression in the superior lateral protocerebrum, lateral horn, antler (Fig. $5 B, C$ ), and mushroom body calyx (Fig. 5D). The syt.eGFP signal was weak in the primary processes of the CSDns in the m-ALT, indicating that syt.eGFP is a reliable marker of presynaptic regions (Fig. 5B). To determine whether there are any other sources of 5 -HT to these olfactory regions, we expressed temperature-sensitive UAS-Diphtheria toxin (UAS-DTI) to ablate the CSDns after complete development of the adult olfactory system (Han et al., 2000). Ablation of the CSDns abolished all 5-HT-immunoreactivity in the AL (Fig. $5 E$ ), mushroom body calyx (Fig. $5 F$ ), and lateral horn (Fig. 5G) as well as most 5-HT immunoreactivity in the superior lateral protocerebrum (Fig. 5G), demonstrating that the CSDns are the sole source of 5-HT innervation across multiple processing stages in the olfactory system.

In the AL, syt.eGFP expression was not equally distributed across all glomeruli (Fig. 5A), and the density of CSDn processes differs between several glomeruli (Singh et al., 2013), suggesting that the CSDns may provide more input to some glomeruli over others. We therefore sought to determine the density of CSDn active zones across AL glomeruli and determine whether CSDn active zone density was stereotyped across animals. Bruchpilot-Short (Brp-Short) is a truncated, nonfunctional form of the endogenous active zone protein Bruchpilot (Brp) (Wagh et al., 2006), which aggregates with endogenous Brp and can be used to visualize active zones. UAS-Brp-Short has been used extensively in Drosophila to label active zones of specific neurons of interest in the olfactory system (Kremer et al., 2010; Christiansen et al., 2011; Mosca and Luo, 2014), neuromuscular synapses 

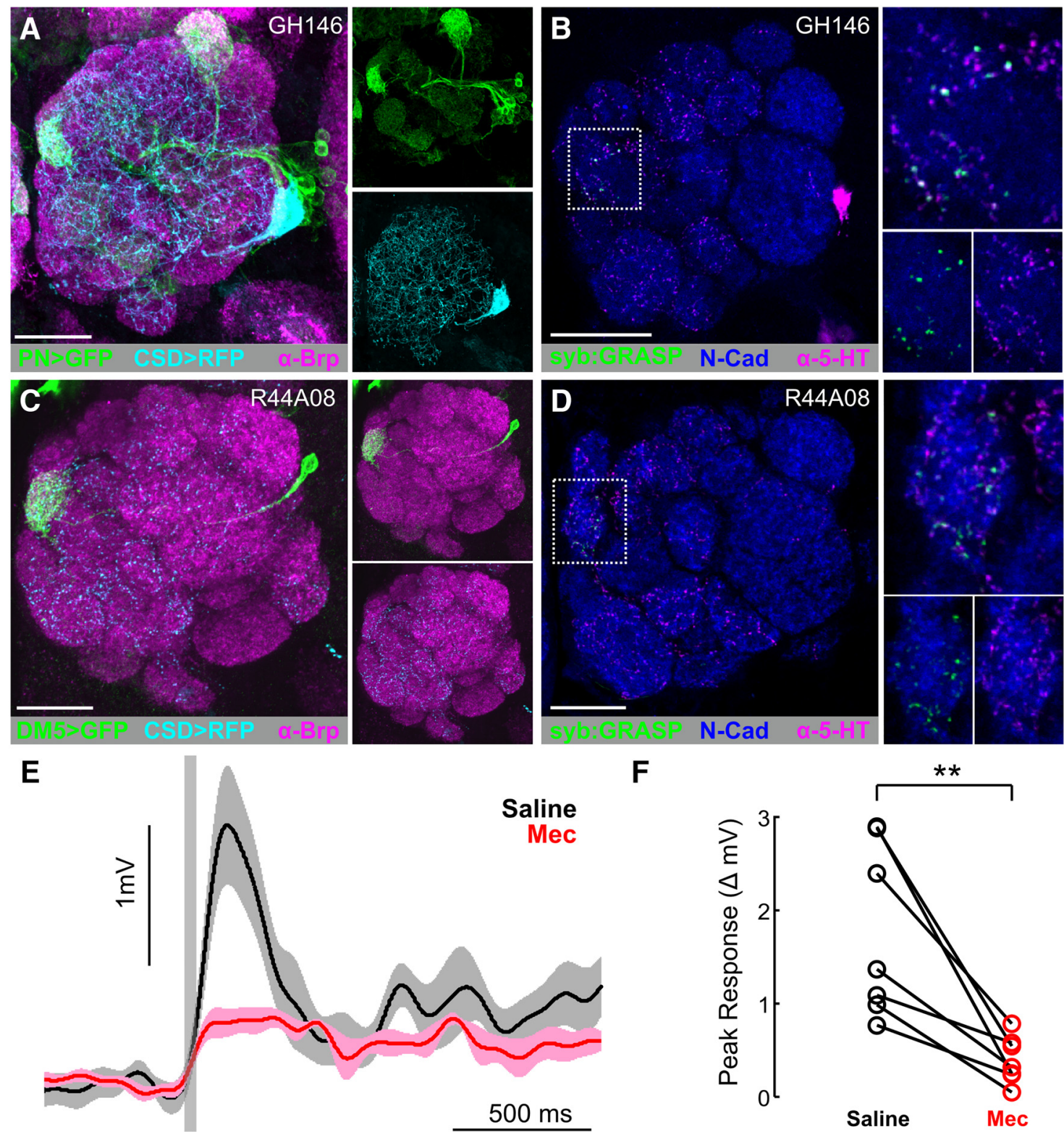

$\mathbf{F}$

**
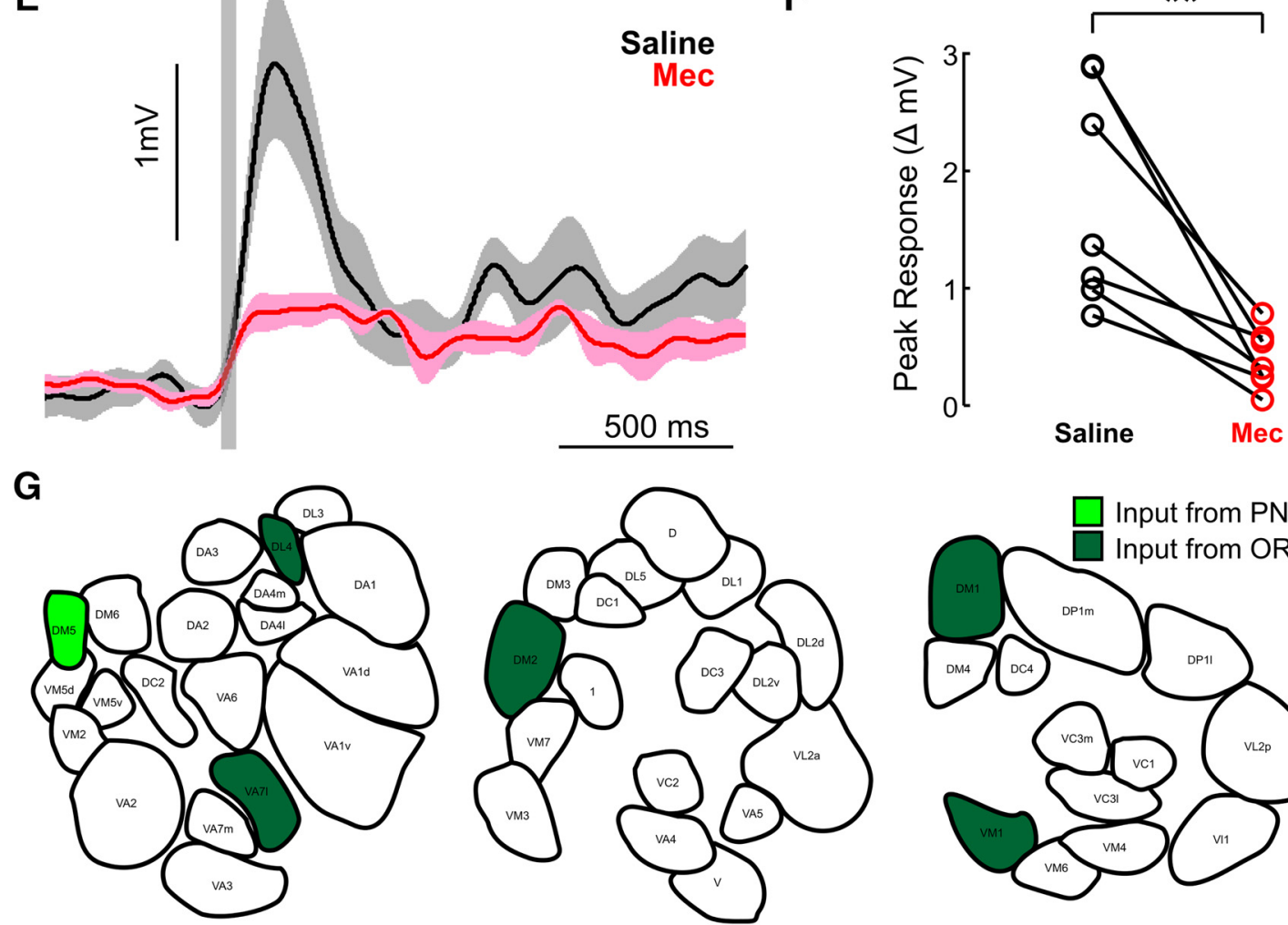

Figure 4. PNs provide glomerulus-specific input to the CSDns in the AL. A, RFP (cyan) expression by the CSDns (via MB465C-spGal4) and GFP (green) expression driven by a subset of PNs (via GH146-LexA::GAD) in the AL. B, syb:GRASP signal between GH146-LexA::GAD (presynaptic) and MB465c-spGal4 (postsynaptic) is localized to the DM5 glomerulus. Reconstituted GFP (green) was identified as GFP-ir only in close association with 5-HT-ir processes (magenta). C, GFP (green) expression of PNs in the DM5 by R44A08-lexA in the AL. D, syb:GRASP signal between R44A08-LexA (presynaptic) and MB465c-spGal4 (postsynaptic) in the DM5 glomerulus. Neuropils are delineated with Brp-ir in magenta in $\boldsymbol{A}$, and $\mathrm{N}$-cadherin-ir delineates neuropil in $\boldsymbol{B}$, (magenta) $\boldsymbol{C}$, and $\boldsymbol{D}$ (blue). $E$, Average CSDn EPSPs evoked by Channelrhodopsin photostimulation of PNs via Mz19-QF. The CSDns were held at $-60 \mathrm{mV}$, and PN activation results in a $\sim 3 \mathrm{mV}$ EPSP in the CSDn (saline; black trace), which is greatly reduced by $100 \mu$ m mecamylamine (Mec; red trace). $\boldsymbol{F}$, Mecamylamine (red circles) significantly decreased the PN evoked CSD EPSPs relative to saline conditions. $n=7$ CSDns. $p=0.0053$ (paired $t$ test). G, Glomeruli in which the CSDns receive input from PNs (light green) or ORNs (dark green) at anterior, middle, and posterior AL depths. Scale bars, $20 \mu \mathrm{m}$. 

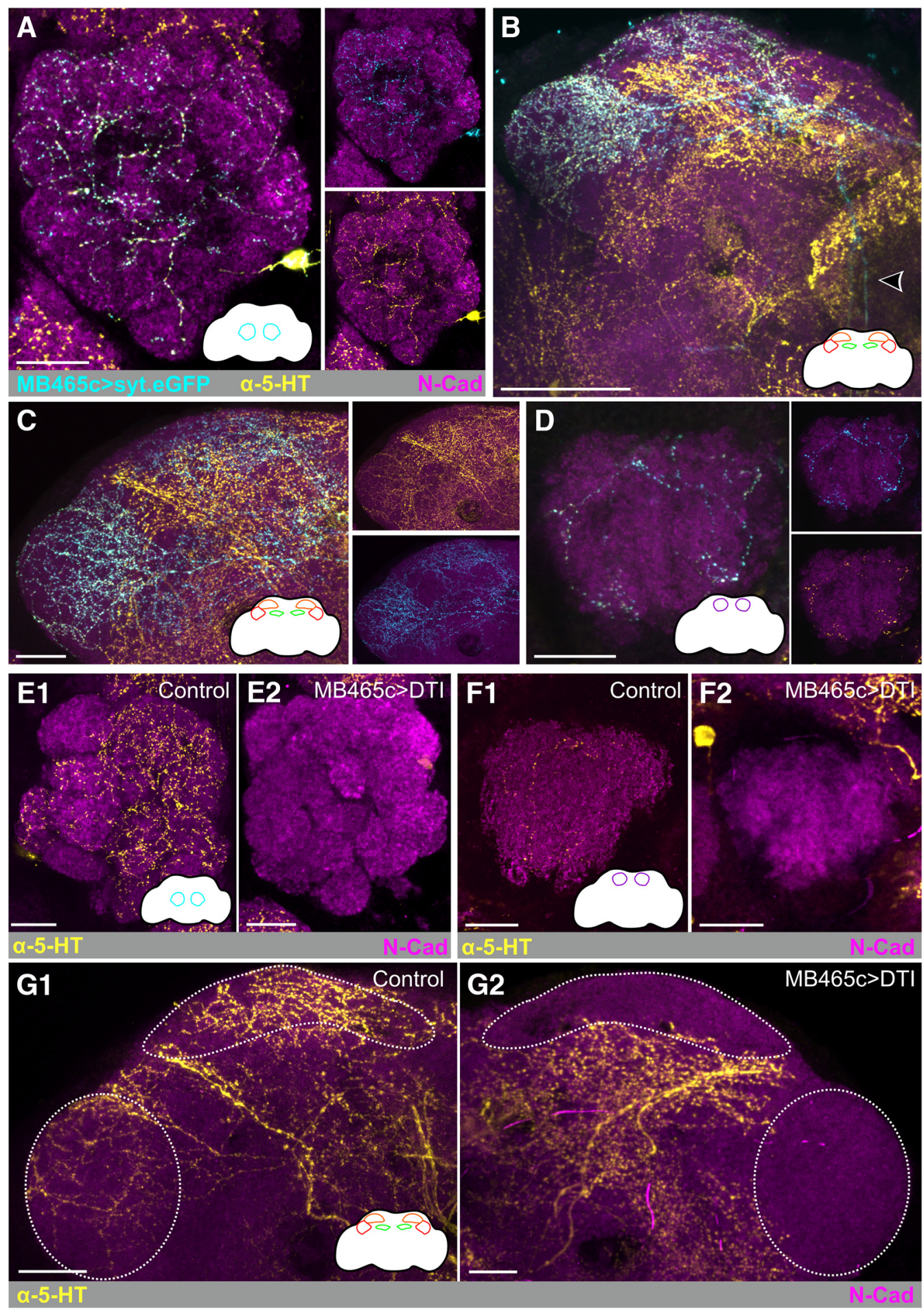

Figure 5. CSDns provide 5-HTergic input to multiple levels of olfactory processing. MB465c-spGal4-driven expression of synaptotagmin GFP (syt.eGFP) expression (cyan) colocalizes with 5-HT-ir processes (yellow) in the antennal lobe $(\boldsymbol{A})$ and LH and superior lateral protocerebrum (SLP) $(\boldsymbol{B})$. syt.eGFP expression is relatively weak in CSDn axons traveling via the mALT (arrow). $\boldsymbol{C}$, MB465CspGal4-driven expression of synaptotagmin GFP (syt.eGFP) expression in the LH and SLP. D, MB465c-spGal4-driven expression of synaptotagmin GFP (syt.eGFP) expression in the mushroom body calyx. E-G, MB465c-driven expression of temperature-sensitive diphtheria toxin via UAS-DTI ablates the CSDns and abolishes all 5-HT-ir (yellow) in the $(\boldsymbol{E 1}, \mathbf{E 2}) \mathrm{AL},(\boldsymbol{F 1}, \boldsymbol{F 2}) \mathrm{Calyx},(\mathbf{G 1}, \mathbf{G 2}) \mathrm{LH}$, as well as a portion of 5-HT-ir in the SLP. N-cadherin-ir delineates neuropil (magenta). Scale bars, $20 \mu \mathrm{m}$.

(Schmid et al., 2008; Fouquet et al., 2009), and visual system (Berger-Müller et al., 2013).

To quantify the number of CSDn active zones in each glomerulus, we simultaneously drove expression of the Bruchpilot Brp-short ${ }_{\text {mStraw }}$ (Fouquet et al., 2009; Mosca and Luo, 2014) and GFP in the CSDns to visualize active zones and the CSDn inner- vation pattern, respectively (Fig. $6 A-C$ ). This allowed us to generate a "heat-map" of glomerulus-specific CSDn synaptic density (Fig. 6D) and to rank-order glomeruli from lowest CSD active zone density (Valv) to the highest (Vc3m; Fig. 6E). The CSDn synaptic density varied significantly across glomeruli $(p<$ 0.0001 , df $=38$, Kruskal-Wallis test, Fig. $6 E$ ), indicating that 


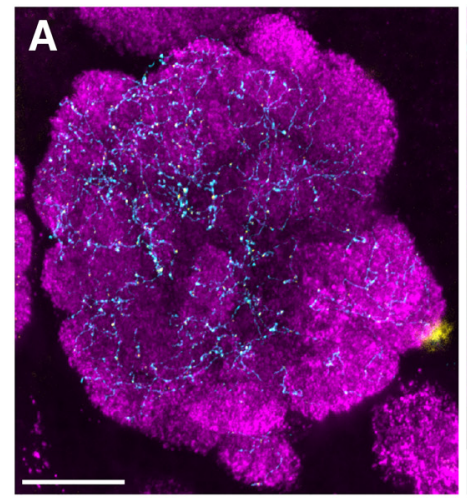

D1

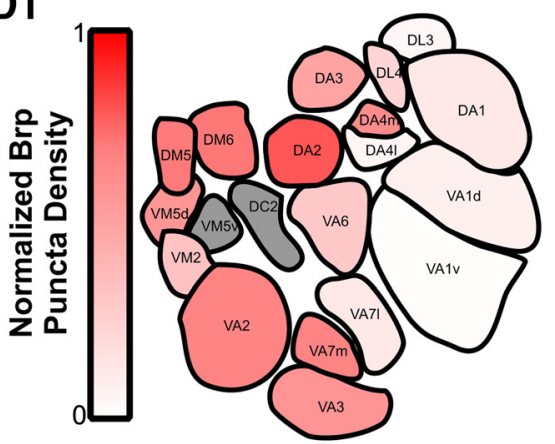

E

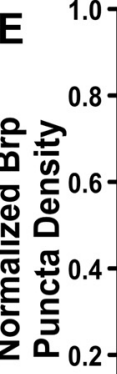

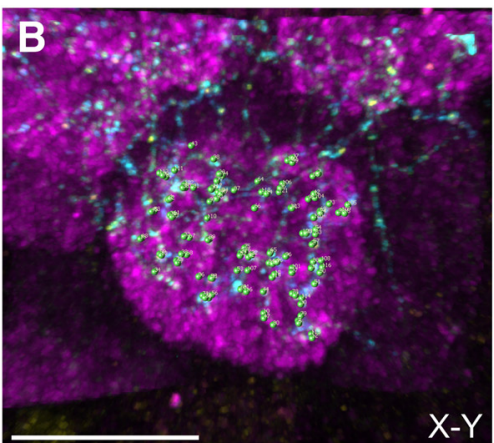

$X-Y$

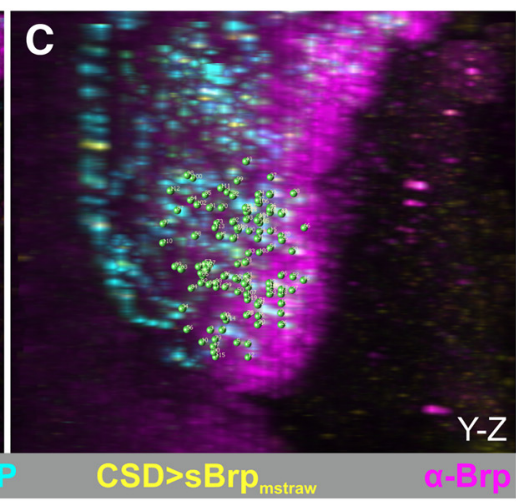

D3
D2

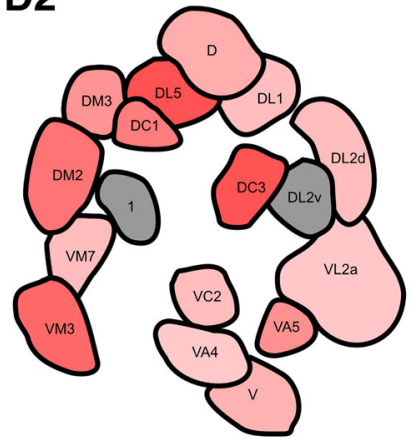

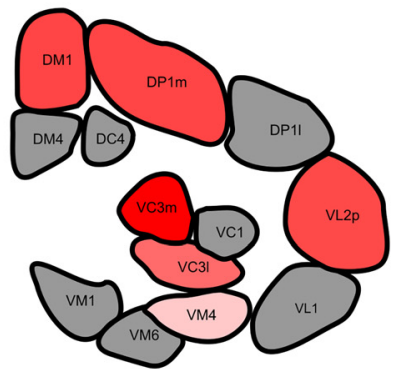

F

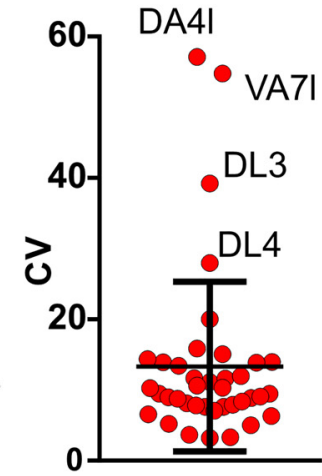

\section{Glomerulus}

Figure 6. Distribution of CSDn active zones is heterogeneous across AL glomeruli. A, MB465c-spGal4-driven expression of Brp-short ${ }_{m S t r a w}$ (yellow) and GFP (cyan) in the AL used to quantify CSDn active zones. Scale bar, $20 \mu \mathrm{m}$. B, C, Example of marked CSDn Brp-short puncta (green) across two 2D planes, (B) X-Y and (C) Y-Z, in the V glomerulus. Brp-ir delineates neuropil (magenta). Scale bar, $10 \mu \mathrm{m}$. D, Normalized Brp-short puncta expressed by the CSDns within glomeruli across the AL at (D1) anterior, (D2) middle, and (D3) posterior depths (N=7-12 animals per glomerulus). Red intensity corresponds to normalized Brp-short puncta density. Glomeruli shown in gray could not be consistently identified and were not analyzed. $E$, Glomeruli rank ordered by normalized Brp-short puncta density. As in $\boldsymbol{D}$, red intensity corresponds to normalized Brp-short puncta density. $\boldsymbol{F}$, Coefficient of variance for each glomerulus. All glomeruli fall into the interquartile range, except for DL3, DA4I, VA7I, and DL4.

there is glomerulus-specific heterogeneity of the synaptic output of these modulatory neurons. The CSDn active zone density varied smoothly across the entire range, suggesting that glomeruli do not belong to discrete groups based on normalized CSDn active zone density. We therefore sought to determine whether the heterogeneity in CSD active zone density across glomeruli was stereotyped across animals, as even identified neurons in invertebrate systems can have a surprising degree of interanimal variability in their morphology (Chou et al., 2010; Otopalik et al., $2017 \mathrm{a}, \mathrm{b})$. To determine the degree of variability in glomerulusspecific CSDn active zone density, we calculated the coefficient of variance for each glomerulus (Fig. $6 F$ ). Only 4 glomeruli (DA4l, VA7l, DL3, and DL4) were outside of the interquartile range across all glomeruli in the dataset. However, these glomeruli likely had higher coefficient of variance values due to their relatively low active zone density values. Thus, the CSDns likely modulate olfactory processing in glomeruli in a nonuniform, yet stereotyped manner.

CSDns are presynaptic to LNs and PNs in the AL, but not ORNs

Finally, we sought to determine the classes of neurons upon which the CSDns synapse. PNs, LNs, and ORNs all express one or more 5-HT receptor type (Sizemore and Dacks, 2016) and are thus potential postsynaptic targets of the CSDns. Optogenetic activation of CSDns elicits responses from both PNs and LNs in adult Drosophila (Zhang and Gaudry, 2016), and electron microscopy studies of the CSDns in larval Drosophila demonstrated 

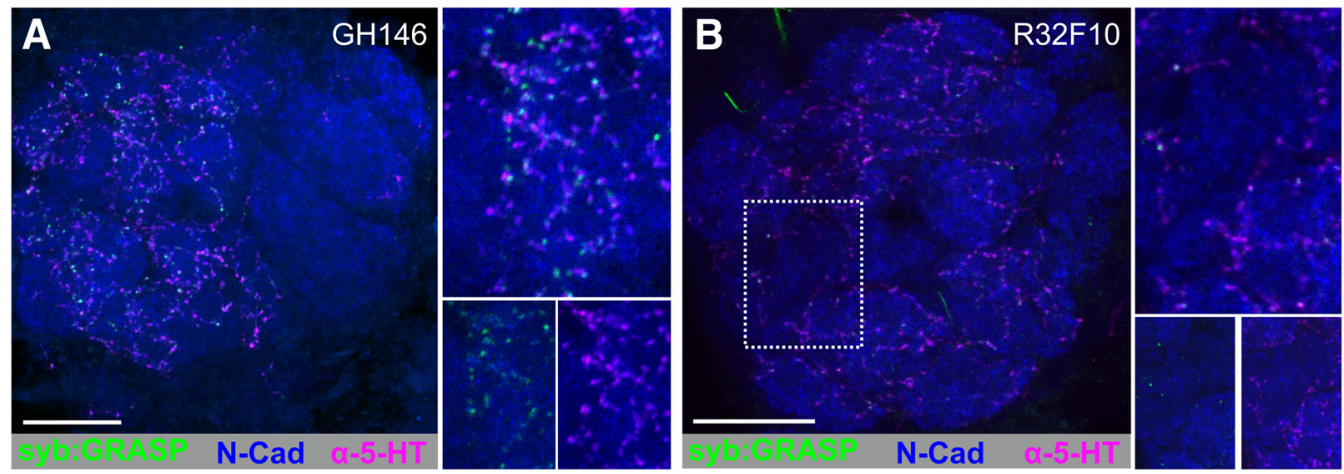

Figure 7. CSDns synapse onto PNs and LNs in the AL. A, syb:GRASP signal between MB465c-spGal4 (presynaptic) and GH146-LexA:GAD (postsynaptic) is distributed throughout the AL. Reconstituted GFP (green) was identified as GFP-ir only in close association with 5-HT-ir processes (magenta). B, syb:GRASP signal between CSDns (presynaptic, via MB465c) and LNs (postsynaptic, via R32F10-LexA). Reconstituted GFP (green) was identified as GFP-ir only in close association with 5-HT-ir processes (magenta). N-cadherin-ir delineates neuropil (blue). Scale bars, $20 \mu \mathrm{m}$.

that the CSDns synapse upon specific LN types (Berck et al., 2016). However, because both the input to the CSDns and the collective distribution of CSDn active zones are glomerulusspecific, it is unclear whether the CSDns synapse upon precise neuron classes in a glomerulus-specific manner as well. Therefore, we drove syb:GRASPspGFP ${ }_{1-10}$ in the CSDns (presynaptic) using MB465c-spGal4 and CD4-spGFP ${ }_{11}$ (postsynaptic) in PNs using GH146-LexA::GAD, GABAergic LNs using R32F10, or ORNs using R10G02 and Or83b-LexA. For PNs, syb:GRASP signal was distributed throughout the AL (Fig. 7A; 13 of 23 brains), as opposed to being restricted to a small number of glomeruli, as was the case for PNs providing synaptic input to the CSDns (Fig. $4 B)$. For LNs, syb:GRASP signal was distributed throughout the AL (Fig. $7 B ; 22$ of 23 brains), suggesting that the glomerulusspecific differences in CSDn active zone density (Fig. 6) are not due to the CSDn synapsing upon a specific neuron class in only select glomeruli. Although ORNs synapse upon the CSDns in select glomeruli (Fig. 3), we did not observe any syb:GRASP signal from CSDns synapsing upon ORNs using the R10G02-LexA (0 of 20). Using the Or83b-LexA, we observed weak to no syb: GRASP signal, indicating that the CSDns synaptic influence on ORNs is little to nonexistent ( $n=7$ brains, data not shown), although we cannot dismiss the possibility of volumetric release. Collectively, our data demonstrate that individual modulatory neurons are not necessarily uniform in their distribution of active zones or the reciprocity of their synaptic interaction, and that modulatory neurons can receive input within their target networks in a neuron class-specific manner.

\section{Discussion}

Nervous systems rely on widely projecting modulatory neurons to adjust the activity of individual neural networks based on ongoing external and internal demands on the organism. These modulatory neurons are often thought to provide top-down input. However, there is increasing evidence that modulatory neurons receive input from the networks that they target and that the connectivity of modulatory neurons is far from uniform. In this study, we characterized the nature of the synaptic relationships between a pair of identified serotonergic modulatory neurons in the olfactory system of Drosophila with their target neural networks. We found that the CSDns receive both glomerulusspecific excitatory and networkwide inhibitory input within the AL. Furthermore, we observed that the distribution of active zones of the CSDns was glomerulus-specific and heterogeneous across the AL. Together, our data demonstrate that individual modulatory neurons can have highly heterogeneous connectivity in terms of the degree that they are connected within a network and the identity of their synaptic partners.

\section{Reciprocal connectivity between CSDns and local interneurons}

At a population level, mammalian modulatory nuclei receive input from a variety of sources, including their target networks. For instance, the raphe nuclei receive input from many cortical and subcortical regions (Nakamura, 2013), including noradrenergic neurons in the locus ceruleus (Baraban and Aghajanian, 1981; Peyron et al., 1996), a brain region that dorsal raphe neurons target (Sim and Joseph, 1993). At the level of identified modulatory neurons, we found connectivity relationships demonstrating that modulatory neurons receive neuron class-specific input. Of the three principal AL neuron classes, LNs provided the most widespread input to the CSDns, suggesting that most of the olfactory information received by the CSDns is through inhibitory lateral interactions. Consistent with this, the majority of tested odors inhibit the CSDns, with those odors activating larger proportions of the olfactory system resulting in stronger inhibition (Zhang and Gaudry, 2016). LNs shape AL network dynamics, refining PN activity before it is relayed to higher-order brain regions (Olsen and Wilson, 2008; Root et al., 2008; Huang et al., 2010; Olsen et al., 2010; Yaksi and Wilson, 2010; Nagel and Wilson, 2011; Root et al., 2011; Liu and Wilson, 2013; Hong and Wilson, 2015; Nagel et al., 2015). GABAergic and glutamatergic LNs synapse upon the CSDns (Fig. 2C,D,F), and both transmitters elicit fast inhibition of the CSDns (Zhang and Gaudry, 2016). The CSDns synapse extensively upon LNs (Fig. 7B) and cause a brief excitation, followed by inhibition (Zhang and Gaudry, 2016). This extensive reciprocal connectivity between the CSDns and the local inhibitory network suggests that interplay between these two neuronal populations likely serves to adjust networkwide dynamics.

\section{Glomerulus-specific input to the CSDns}

Within the AL, the CSDns receive little input from excitatory neurons, but the input they do receive is glomerulus-specific, suggesting that the CSDns may be fairly sparse in their breadth of odor tuning. Despite broad overlap of ORN and CSDn innervation of the two fly lines we used (Fig. $3 A-C$ ), we found that ORNs synapse onto CSDns in only a few glomeruli (Fig. $3 B, D$ ), suggesting that volatile chemicals, which activate the chemoreceptive 
proteins expressed by those ORN types, will activate the CSDns. For instance, ORNs innervating the VM1 glomerulus synapse upon the CSDns. These ORNs express Ir92a, which mediates the detection of ammonia (Min et al., 2013); and consistent with sparse odor tuning, ammonia is the only odor known to excite CSDns (Zhang and Gaudry, 2016). The CSDns also receive input from ORNs responsive to ecologically relevant odors, including the Or46a-expressing ORNs that innervate the VA7l and respond to phenol, a behavioral repellant in the fecal matter of carnivores (Mansourian et al., 2016), as well as the Or49a/85f-expressing ORNs that innervate the DL4 (Couto et al., 2005; Fishilevich and Vosshall, 2005) and respond to parasitoid-derived volatiles (Ebrahim et al., 2015). Although this suggests that the CSDns are activated by specific odor lines, some of the ORNs providing input to the CSDns are much more broadly tuned to volatiles, such as the Or22a ORNs innervating the DM2 (Hallem and Carlson, 2004; Hallem et al., 2004). Interestingly, the synaptic relationship between ORNs and the CSDns appears to shift during metamorphosis, likely reflecting changes in the relevance of specific odors for different life stages. In the larvae, Or74a- and Or82a-expressing ORNs synapse onto the CSDns (Berck et al., 2016). However, Or74a is not expressed in adults, and adult Or82a-expressing ORNs do not synapse upon the CSDns. Furthermore, geranyl acetate, the cognate ligand of Or82a, does not activate the CSDns (Zhang and Gaudry, 2016). In contrast, the CSDns synapse upon LNs in larvae (Berck et al., 2016) and adults, demonstrating that certain connectivity rules are recapitulated during metamorphosis.

The CSDns also receive glomerulus-specific excitatory input from PNs innervating the DM5 glomerulus (Fig. 4), which are activated by high concentrations of apple cider vinegar, resulting in behavioral aversion (Semmelhack and Wang, 2009). This glomerulus-specific excitatory input to the CSDns suggests that, while most odors inhibit the CSDns due to activation of GABAergic and glutamatergic LNs, there are likely a small subset of "private" odors (i.e., odors activating sparse sets of glomeruli) that provide excitatory drive to the CSDns.

The AL neuron classes studied here differed from each other in terms of the reciprocity of their synaptic relationships with the CSDns. Several ORN types synapse onto the CSDns, but we found little evidence for the CSDns synapsing onto ORNs. This is consistent with observations that with $\mathrm{GABA}_{\mathrm{B}}$ receptor blockade, isolated ORN axons are not affected by 5-HT (Dacks et al., 2009) and that in Manduca, CSDn processes do not overlap with ORNs (Sun et al., 1993; Lizbinski et al., 2016). However, ORNs express the 5-HT2B receptor (Sizemore and Dacks, 2016), suggesting that ORNs may receive significant serotonergic input from source(s) other than the CSDns, such as bulk release of 5-HT in the hemolymph, that activates ORN 5-HT receptors expressed in the antennae. This would be consistent with reports of CSDnindependent modulation of PN odor-evoked responses in the AL (Zhang and Gaudry, 2016). The synaptic relationship between PNs and the CSDns shows a different direction of reciprocity relative to ORNs. PNs synapse onto the CSDns in just one glomerulus, yet the CSDns synapse onto PNs broadly throughout the AL (Fig. 7A), suggesting that the CSDns have widespread effects upon PNs, yet PNs as a population have less of an influence upon the CSDns. In contrast to both ORNs and PNs, LNs synapse onto the CSDns widely throughout the AL and the CSDns synapse back onto LNs in a similar manner. This suggests a more evenly reciprocal relationship between CSDns and LNs.

\section{Modulatory nuclei can provide heterogeneous output}

Populations of neurons within modulatory nuclei are highly heterogeneous with regards to their anatomy, physiology, genetic lineage, and functionality (Vandermaelen and Aghajanian, 1983; Kirby et al., 2003; Urbain et al., 2006; Calizo et al., 2011; Hale and Lowry, 2011; Okaty et al., 2015; Faget et al., 2016). For instance, the dorsal raphe nucleus (DRN) and medial raphe nucleus in mice innervate distinct regions of the olfactory bulb, with DRN neurons innervating the granule cell layer and medial raphe nucleus neurons innervating the glomerular layer, demonstrating nonuniform output across serotonergic nuclei (McLean and Shipley, 1987; Steinfeld et al., 2015). We were able to quantify this structural heterogeneity at the level of the active zones of identified serotonergic neurons and found that, although active zone density of a single modulatory neuron varies across glomeruli, it is actually highly stereotyped. Raphe projections to the olfactory bulb also differentially affect mitral cells and tufted cells (Kapoor et al., 2016), further suggesting that, similar to the CSDns, raphe output is neuron class-specific and that individual raphe neurons may have glomerulus-specific targeting. Nonuniform synaptic output may also be a distinctive feature of individual modulatory neurons. The synaptic output of PNs (Stocker et al., 1990; Malun, 1991; Sun et al., 1997; Abel et al., 2001; Namiki and Kanzaki, 2008; Rybak et al., 2016) and ORNs (Mosca and Luo, 2014) is uniform across glomeruli, suggesting that uniformity of synaptic output may differ between principal AL and modulatory neurons. The density of CSDn active zones differed widely between glomeruli yet was stereotyped within each glomerulus from animal to animal, suggesting that individual modulatory neurons provide differential input to specific subregions. This does not necessarily isolate these glomeruli from the effects of neuromodulators, as modulation of lateral interactions could allow a modulatory neuron to influence activity in brain regions to which they do not project. Furthermore, syt.eGFP expression by the CSDns was observed in the LH and calyx (Fig. $5 B-D$ ), indicating that, in addition to nonuniform effects within the AL, the CSDns simultaneously influence odor coding across multiple processing stages.

In conclusion, together, our data suggest that, within the AL, the CSDns integrate networkwide inhibition and glomerulusspecific excitation. The CSDns appear to have a direct "topdown" relationship with PNs as they receive relatively little input from PNs yet broadly synapse upon these output neurons. In contrast, the CSDns have a "bottom-up" relationship with ORNs as they receive input from specific ORNs but do not synapse on these input neurons. The degree of synaptic reciprocity between the CSDns and LNs suggests that the influence of the CSDns is likely tempered by the overall degree of activation by the network (as communicated by LN activity). LNs release both fast transmitters, like GABA and glutamate, and neuropeptides (Carlsson et al., 2010), suggesting that the communication between LNs and the CSDns may be temporally complex. LNs are incredibly diverse, so future work will be needed to determine the influence of the CSDns upon specific LN subtypes that play distinct functional roles in olfactory coding. For instance, populations of cortical interneurons are differentially modulated to shift the balance between inhibitory states (Beierlein et al., 2000), and a similar mechanism has been suggested for the larval AL (Berck et al., 2016). Finally, the output of the CSDns appears to be heterogeneous, yet stereotyped, suggesting that the CSDns could potentially serve to establish a network state within the $\mathrm{AL}$, as has been suggested for raphe neurons in the OB (Liu et al., 2012) and demonstrated by DRN in the prefrontal cortex (Puig et al., 2010), 
with the opportunity for stimulus-specific refinement. Future studies based on the connectivity established here can elucidate how individual modulatory neurons, such as the CSDns, integrate networkwide inhibition and stimulus specific excitation to affect odor coding. Determining the connectivity of individual modulatory neurons therefore provides a framework for dissecting the guiding principles by which neuromodulation shapes sensory network dynamics.

\section{References}

Abel R, Rybak J, Menzel R (2001) Structure and response patterns of olfactory interneurons in the honeybee, Apis mellifera. J Comp Neurol 437: 363-383. CrossRef Medline

Alekseyenko OV, Lee C, Kravitz EA (2010) Targeted manipulation of serotonergic neurotransmission affects the escalation of aggression in adult male Drosophila melanogaster. PLoS One 5:e10806. CrossRef Medline

Andrade R, Haj-Dahmane S (2013) Serotonin neuron diversity in the dorsal raphe. ACS Chem Neurosci 4:22-25. CrossRef Medline

Aso Y, Hattori D, Yu Y, Johnston RM, Iyer NA, Ngo TT, Dionne H, Abbott LF, Axel R, Tanimoto H, Rubin GM (2014) The neuronal architecture of the mushroom body provides a logic for associative learning. eLife 3:e04577. CrossRef Medline

Bang SJ, Jensen P, Dymecki SM, Commons KG (2012) Projections and interconnections of genetically defined serotonin neurons in mice. Eur J Neurosci 35:85-96. CrossRef Medline

Baraban JM, Aghajanian GK (1981) Noradrenergic innervation of serotonergic neurons in the dorsal raphe: demonstration by electron microscopic autoradiography. Brain Res 204:1-11. CrossRef Medline

Beierlein M, Gibson JR, Connors BW (2000) A network of electrically coupled interneurons drives synchronized inhibition in neocortex. Nat Neurosci 3:904-910. CrossRef Medline

Berck ME, Khandelwal A, Claus L, Hernandez-Nunez L, Si G, Tabone CJ, Li F, Truman JW, Fetter RD, Louis M, Samuel AD, Cardona A (2016) The wiring diagram of a glomerular olfactory system. eLife 5:e14859.CrossRef Medline

Berger-Müller S, Sugie A, Takahashi F, Tavosanis G, Hakeda-Suzuki S, Suzuki T (2013) Assessing the role of cell-surface molecules in central synaptogenesis in the Drosophila visual system. PLoS One 8:e83732. CrossRef Medline

Calizo LH, Akanwa A, Ma X, Pan YZ, Lemos JC, Craige C, Heemstra LA, Beck SG (2011) Raphe serotonin neurons are not homogenous: electrophysiological, morphological and neurochemical evidence. Neuropharmacology 61:524-543. CrossRef Medline

Carlsson MA, Diesner M, Schachtner J, Nässel DR (2010) Multiple neuropeptides in the Drosophila antennal lobe suggest complex modulatory circuits. J Comp Neurol 518:3359-3380. CrossRef Medline

Chou YH, Spletter ML, Yaksi E, Leong JC, Wilson RI, Luo L (2010) Diversity and wiring variability of olfactory local interneurons in the Drosophila antennal lobe. Nat Neurosci 13:439-449. CrossRef Medline

Christiansen F, Zube C, Andlauer TF, Wichmann C, Fouquet W, Owald D, Mertel S, Leiss F, Tavosanis G, Luna AJ, Fiala A, Sigrist SJ (2011) Presynapses in Kenyon cell dendrites in the mushroom body calyx of Drosophila. J Neurosci 31:9696-9707. CrossRef Medline

Couto A, Alenius M, Dickson BJ (2005) Molecular, anatomical, and functional organization of the Drosophila olfactory system. Curr Biol 15:15351547. CrossRef Medline

Dacks AM, Christensen TA, Hildebrand JG (2006) Phylogeny of a serotoninimmunoreactive neuron in the primary olfactory center of the insect brain. J Comp Neurol 498:727-746. CrossRef Medline

Dacks AM, Green DS, Root CM, Nighorn AJ, Wang JW (2009) Serotonin modulates olfactory processing in the antennal lobe of Drosophila. J Neurogenet 23:366-377. CrossRef Medline

Diao F, Ironfield H, Luan H, Diao F, Shropshire WC, Ewer J, Marr E, Potter CJ, Landgraf M, White BH (2015) Plug-and-play genetic access to drosophila cell types using exchangeable exon cassettes. Cell Rep 10: 1410-1421. CrossRef Medline

Ebrahim SA, Dweck HK, Stökl J, Hofferberth JE, Trona F, Weniger K, Rybak J, Seki Y, Stensmyr MC, Sachse S, Hansson BS, Knaden M (2015) Drosophila avoids parasitoids by sensing their semiochemicals via a dedicated olfactory circuit. PLoS Biol 13:e1002318. CrossRef Medline

Faget L, Osakada F, Duan J, Ressler R, Johnson AB, Proudfoot JA, Yoo JH, Callaway EM, Hnasko TS (2016) Afferent inputs to neurotransmitter- defined cell types in the ventral tegmental area. Cell Rep 15:2796-2808. CrossRef Medline

Feinberg EH, Vanhoven MK, Bendesky A, Wang G, Fetter RD, Shen K, Bargmann CI (2008) GFP Reconstitution Across Synaptic Partners (GRASP) defines cell contacts and synapses in living nervous systems. Neuron 57: 353-363. CrossRef Medline

Fishilevich E, Vosshall LB (2005) Genetic and functional subdivision of the Drosophila antennal lobe. Curr Biol 15:1548-1553. CrossRef Medline

Fouquet W, Owald D, Wichmann C, Mertel S, Depner H, Dyba M, Hallermann S, Kittel RJ, Eimer S, Sigrist SJ (2009) Maturation of active zone assembly by Drosophila Bruchpilot. J Cell Biol 186:129-145. CrossRef Medline

Gordon MD, Scott K (2009) Motor control in a Drosophila taste circuit. Neuron 61:373-384. CrossRef Medline

Hale MW, Lowry CA (2011) Functional topography of midbrain and pontine serotonergic systems: implications for synaptic regulation of serotonergic circuits. Psychopharmacology (Berl) 213:243-264. CrossRef Medline

Hale MW, Shekhar A, Lowry CA (2012) Stress-related serotonergic systems: implications for symptomatology of anxiety and affective disorders. Cell Mol Neurobiol 32:695-708. CrossRef Medline

Hallem EA, Carlson JR (2004) The odor coding system of Drosophila. Trends Genet 20:453-459. CrossRef Medline

Hallem EA, Ho MG, Carlson JR (2004) The molecular basis of odor coding in the Drosophila antenna. Cell 117:965-979. CrossRef Medline

Han DD, Stein D, Stevens LM (2000) Investigating the function of follicular subpopulations during Drosophila oogenesis through hormone-dependent enhancer-targeted cell ablation. Development 127:573-583. Medline

Hill ES, Iwano M, Gatellier L, Kanzaki R (2002) Morphology and physiology of the serotonin-immunoreactive putative antennal lobe feedback neuron in the male silkmoth Bombyx mori. Chem Senses 27:475-483. CrossRef Medline

Hill ES, Okada K, Kanzaki R (2003) Visualization of modulatory effects of serotonin in the silkmoth antennal lobe. J Exp Biol 206:345-352. CrossRef Medline

Hong EJ, Wilson RI (2015) Simultaneous encoding of odors by channels with diverse sensitivity to inhibition. Neuron 85:573-589. CrossRef Medline

Hong W, Mosca TJ, Luo L (2012) Teneurins instruct synaptic partner matching in an olfactory map. Nature 484:201-207. CrossRef Medline

Huang J, Zhang W, Qiao W, Hu A, Wang Z (2010) Functional connectivity and selective odor responses of excitatory local interneurons in Drosophila antennal lobe. Neuron 67:1021-1033. CrossRef Medline

Hurley LM, Devilbiss DM, Waterhouse BD (2004) A matter of focus: monoaminergic modulation of stimulus coding in mammalian sensory networks. Curr Opin Neurobiol 14:488-495. CrossRef Medline

Ito K, Shinomiya K, Ito M, Armstrong JD, Boyan G, Hartenstein V, Harzsch S, Heisenberg M, Homberg U, Jenett A, Keshishian H, Restifo LL, Rössler W, Simpson JH, Strausfeld NJ, Strauss R, Vosshall LB (2014) A systematic nomenclature for the insect brain. Neuron 81:755-765. CrossRef Medline

Iwai Y, Usui T, Hirano S, Steward R, Takeichi M, Uemura T (1997) Axon patterning requires DN-cadherin, a novel neuronal adhesion receptor, in the Drosophila embryonic CNS. Neuron 19:77-89. CrossRef Medline

Jenett A, Rubin GM, Ngo TT, Shepherd D, Murphy C, Dionne H, Pfeiffer BD, Cavallaro A, Hall D, Jeter J, Iyer N, Fetter D, Hausenfluck JH, Peng H, Trautman ET, Svirskas RR, Myers EW, Iwinski ZR, Aso Y, DePasquale GM, et al. (2012) A GAL4-driver line resource for Drosophila neurobiology. Cell Rep 2:991-1001. CrossRef Medline

Jensen P, Farago AF, Awatramani RB, Scott MM, Deneris ES, Dymecki SM (2008) Redefining the serotonergic system by genetic lineage. Nat Neurosci 11:417-419. CrossRef Medline

Joseph RM, Carlson JR (2015) Drosophila chemoreceptors: a molecular interface between the chemical world and the brain. Trends Genet 31:683695. CrossRef Medline

Kapoor V, Provost AC, Agarwal P, Murthy VN (2016) Activation of raphe nuclei triggers rapid and distinct effects on parallel olfactory bulb output channels. Nat Neurosci 19:271-282. CrossRef Medline

Kazama H, Wilson RI (2009) Origins of correlated activity in an olfactory circuit. Nat Neurosci 12:1136-1144. CrossRef Medline

Kent KS, Hoskins SG, Hildebrand JG (1987) A novel serotonin-immunoreactive neuron in the antennal lobe of the sphinx moth Manduca sexta 
persists throughout postembryonic life. J Neurobiol 18:451-465. CrossRef Medline

Kirby LG, Pernar L, Valentino RJ, Beck SG (2003) Distinguishing characteristics of serotonin and non-serotonin-containing cells in the dorsal raphe nucleus: electrophysiological and immunohistochemical studies. Neuroscience 116:669-683. CrossRef Medline

Kloppenburg P, Hildebrand JG (1995) Neuromodulation by 5-hydroxytryptamine in the antennal lobe of the sphinx moth Manduca sexta. J Exp Biol 198: 603-611. Medline

Kloppenburg P, Ferns D, Mercer AR (1999) Serotonin enhances central olfactory neuron responses to female sex pheromone in the male sphinx moth Manduca sexta. J Neurosci 19:8172-8181. Medline

Kremer MC, Christiansen F, Leiss F, Paehler M, Knapek S, Andlauer TF, Förstner F, Kloppenburg P, Sigrist SJ, Tavosanis G (2010) Structural long-term changes at mushroom body input synapses. Curr Biol 20: 1938-1944. CrossRef Medline

Lai SL, Lee T (2006) Genetic mosaic with dual binary transcriptional systems in Drosophila. Nat Neurosci 9:703-709. CrossRef Medline

Lai SL, Awasaki T, Ito K, Lee T (2008) Clonal analysis of Drosophila antennal lobe neurons: diverse neuronal architectures in the lateral neuroblast lineage. Development 135:2883-2893. CrossRef Medline

Liu S, Aungst JL, Puche AC, Shipley MT (2012) Serotonin modulates the population activity profile of olfactory bulb external tufted cells. J Neurophysiol 107:473-483. CrossRef Medline

Liu WW, Wilson RI (2013) Glutamate is an inhibitory neurotransmitter in the Drosophila olfactory system. Proc Natl Acad Sci U S A 110:1029410299. CrossRef Medline

Lizbinski KM, Metheny JD, Bradley SP, Kesari A, Dacks AM (2016) The anatomical basis for modulatory convergence in the antennal lobe of Manduca sexta. J Comp Neurol 524:1859-1875. CrossRef Medline

Lottem E, Lörincz ML, Mainen ZF (2016) Optogenetic activation of dorsal raphe serotonin neurons rapidly inhibits spontaneous but not odorevoked activity in olfactory cortex. J Neurosci 36:7-18. CrossRef Medline

Luan H, Peabody NC, Vinson CR, White BH (2006) Refined spatial manipulation of neuronal function by combinatorial restriction of transgene expression. Neuron 52:425-436. CrossRef Medline

Macpherson LJ, Zaharieva EE, Kearney PJ, Alpert MH, Lin TY, Turan Z, Lee $\mathrm{CH}$, Gallio M (2015) Dynamic labelling of neural connections in multiple colours by trans-synaptic fluorescence complementation. Nat Commun 6:10024. CrossRef Medline

Maimon G, Straw AD, Dickinson MH (2010) Active flight increases the gain of visual motion processing in Drosophila. Nat Neurosci 13:393-399. CrossRef Medline

Malun D (1991) Inventory and distribution of synapses of identified uniglomerular projection neurons in the antennal lobe of Periplaneta americana. J Comp Neurol 305:348-360. CrossRef Medline

Mansourian S, Corcoran J, Enjin A, Löfstedt C, Dacke M, Stensmyr MC (2016) Fecal-derived phenol induces egg-laying aversion in Drosophila. Curr Biol 26:2762-2769. CrossRef Medline

Martin JP, Beyerlein A, Dacks AM, Reisenman CE, Riffell JA, Lei H, Hildebrand JG (2011) The neurobiology of insect olfaction: sensory processing in a comparative context. Prog Neurobiol 95:427-447. CrossRef Medline

McLean JH, Shipley MT (1987) Serotonergic afferents to the rat olfactory bulb: I. Origins and laminar specificity of serotonergic inputs in the adult rat. J Neurosci 7:3016-3028. Medline

Merzin M (2008) Applying stereological method in radiology: volume measurement. Bachelor's thesis, University of Tartu.

Min S, Ai M, Shin SA, Suh GS (2013) Dedicated olfactory neurons mediating attraction behavior to ammonia and amines in Drosophila. Proc Natl Acad Sci U S A 110:E1321-E1329. CrossRef Medline

Mosca TJ, Luo L (2014) Synaptic organization of the Drosophila antennal lobe and its regulation by the Teneurins. eLife 3:e03726. CrossRef Medline

Nagel KI, Wilson RI (2011) Biophysical mechanisms underlying olfactory receptor neuron dynamics. Nat Neurosci 14:208-216. CrossRef Medline

Nagel KI, Hong EJ, Wilson RI (2015) Synaptic and circuit mechanisms promoting broadband transmission of olfactory stimulus dynamics. Nat Neurosci 18:56-65. CrossRef Medline

Nakamura K (2013) The role of the dorsal raphe nucleus in reward-seeking behavior. Front Integr Neurosci 7:60. CrossRef Medline

Namiki S, Kanzaki R (2008) Reconstructing the population activity of olfactory output neurons that innervate identifiable processing units. Front Neural Circuits 2:1. CrossRef Medline
Ogawa SK, Cohen JY, Hwang D, Uchida N, Watabe-Uchida M (2014) Organization of monosynaptic inputs to the serotonin and dopamine neuromodulatory systems. Cell Rep 8:1105-1118. CrossRef Medline

O'Hearn E, Molliver ME (1984) Organization of raphe-cortical projections in rat: a quantitative retrograde study. Brain Res Bull 13:709-726. CrossRef Medline

Okaty BW, Freret ME, Rood BD, Brust RD, Hennessy ML, deBairos D, Kim JC, Cook MN, Dymecki SM (2015) Multi-scale molecular deconstruction of the serotonin neuron system. Neuron 88:774-791. CrossRef Medline

Olsen SR, Wilson RI (2008) Lateral presynaptic inhibition mediates gain control in an olfactory circuit. Nature 452:956-960. CrossRef Medline

Olsen SR, Bhandawat V, Wilson RI (2010) Divisive normalization in olfactory population codes. Neuron 66:287-299. CrossRef Medline

Otopalik AG, Sutton AC, Banghart M, Marder E (2017a) When complex neuronal structures may not matter. eLife 6:e23508. CrossRef Medline

Otopalik AG, Goeritz ML, Sutton AC, Brookings T, Guerini C, Marder E (2017b) Sloppy morphological tuning in identified neurons of the crustacean stomatogastric ganglion. eLife 6:e22352. CrossRef Medline

Owald D, Fouquet W, Schmidt M, Wichmann C, Mertel S, Depner H, Christiansen F, Zube C, Quentin C, Körner J, Urlaub H, Mechtler K, Sigrist SJ (2010) A Syd-1 homologue regulates pre- and postsynaptic maturation in Drosophila. J Cell Biol 188:565-579. CrossRef Medline

Pech U, Pooryasin A, Birman S, Fiala A (2013) Localization of the contacts between Kenyon cells and aminergic neurons in the Drosophila melanogaster brain using SplitGFP reconstitution. J Comp Neurol 521:39924026. CrossRef Medline

Peng H, Ruan Z, Long F, Simpson JH, Myers EW (2010) V3D enables realtime 3D visualization and quantitative analysis of large-scale biological image data sets. Nat Biotechnol 28:348-353. CrossRef Medline

Petzold GC, Hagiwara A, Murthy VN (2009) Serotonergic modulation of odor input to the mammalian olfactory bulb. Nat Neurosci 12:784-791. CrossRef Medline

Peyron C, Luppi PH, Fort P, Rampon C, Jouvet M (1996) Lower brainstem catecholamine afferents to the rat dorsal raphe nucleus. J Comp Neurol 364:402-413. CrossRef Medline

Pfeiffer BD, Ngo TT, Hibbard KL, Murphy C, Jenett A, Truman JW, Rubin GM (2010) Refinement of tools for targeted gene expression in Drosophila. Genetics 186:735-755. CrossRef Medline

Pollak Dorocic I, Fürth D, Xuan Y, Johansson Y, Pozzi L, Silberberg G, Carlén M, Meletis K (2014) A whole-brain atlas of inputs to serotonergic neurons of the dorsal and median raphe nuclei. Neuron 83:663-678. CrossRef Medline

Pooryasin A, Fiala A (2015) Identified serotonin-releasing neurons induce behavioral quiescence and suppress mating in Drosophila. J Neurosci 35: 12792-12812. CrossRef Medline

Puig MV, Watakabe A, Ushimaru M, Yamamori T, Kawaguchi Y (2010) Serotonin modulates fast-spiking interneuron and synchronous activity in the rat prefrontal cortex through 5-HT1A and 5-HT2A receptors. J Neurosci 30:2211-2222. CrossRef Medline

Root CM, Masuyama K, Green DS, Enell LE, Nässel DR, Lee CH, Wang JW (2008) A presynaptic gain control mechanism fine-tunes olfactory behavior. Neuron 59:311-321. CrossRef Medline

Root CM, Ko KI, Jafari A, Wang JW (2011) Presynaptic facilitation by neuropeptide signaling mediates odor-driven food search. Cell 145:133-144. CrossRef Medline

Roy B, Singh AP, Shetty C, Chaudhary V, North A, Landgraf M, Vijayraghavan K, Rodrigues V (2007) Metamorphosis of an identified serotonergic neuron in the Drosophila olfactory system. Neural Dev 2:20. CrossRef Medline

Rybak J, Talarico G, Ruiz S, Arnold C, Cantera R, Hansson BS (2016) Synaptic circuitry of identified neurons in the antennal lobe of Drosophila melanogaster. J Comp Neurol 524:1920-1956. CrossRef Medline

Schmid A, Hallermann S, Kittel RJ, Khorramshahi O, Frölich AM, Quentin C, Rasse TM, Mertel S, Heckmann M, Sigrist SJ (2008) Activity-dependent site-specific changes of glutamate receptor composition in vivo. Nat Neurosci 11:659-666. CrossRef Medline

Semmelhack JL, Wang JW (2009) Select Drosophila glomeruli mediate innate olfactory attraction and aversion. Nature 459:218-223. CrossRef Medline

Sim LJ, Joseph SA (1993) Dorsal raphe nucleus efferents: termination in peptidergic fields. Peptides 14:75-83. CrossRef Medline 
Singh AP, Das RN, Rao G, Aggarwal A, Diegelmann S, Evers JF, Karandikar H, Landgraf M, Rodrigues V, Vijayraghavan K (2013) Sensory neuronderived eph regulates glomerular arbors and modulatory function of a central serotonergic neuron. PLoS Genet 9:e1003452. CrossRef Medline

Sitaraman D, LaFerriere H, Birman S, Zars T (2012) Serotonin is critical for rewarded olfactory short-term memory in Drosophila. J Neurogenet 26: 238-244. CrossRef Medline

Sizemore TR, Dacks AM (2016) Serotonergic modulation differentially targets distinct network elements within the antennal lobe of Drosophila melanogaster. Sci Rep 6:37119. CrossRef Medline

Steinfeld R, Herb JT, Sprengel R, Schaefer AT, Fukunaga I (2015) Divergent innervation of the olfactory bulb by distinct raphe nuclei. J Comp Neurol 523:805-813. CrossRef Medline

Stocker RF, Lienhard MC, Borst A, Fischbach KF (1990) Neuronal architecture of the antennal lobe in Drosophila melanogaster. Cell Tissue Res 262: 9-34. CrossRef Medline

Sun XJ, Tolbert LP, Hildebrand JG (1993) Ramification pattern and ultrastructural characteristics of the serotonin-immunoreactive neuron in the antennal lobe of the moth Manduca sexta: a laser scanning confocal and electron microscopic study. J Comp Neurol 338:5-16. CrossRef Medline

Sun XJ, Tolbert LP, Hildebrand JG (1997) Synaptic organization of the uniglomerular projection neurons of the antennal lobe of the moth Manduca sexta: a laser scanning confocal and electron microscopic study. J Comp Neurol 379:2-20. CrossRef Medline

Urbain N, Creamer K, Debonnel G (2006) Electrophysiological diversity of the dorsal raphe cells across the sleep-wake cycle of the rat. J Physiol 573:679-695. CrossRef Medline

Vallés AM, White K (1988) Serotonin-containing neurons in Drosophila melanogaster: development and distribution. J Comp Neurol 268:414-428. CrossRef Medline
Vandermaelen CP, Aghajanian GK (1983) Electrophysiological and pharmacological characterization of serotonergic dorsal raphe neurons recorded extracellularly and intracellularly in rat brain slices. Brain Res 289:109-119. CrossRef Medline

Wagh DA, Rasse TM, Asan E, Hofbauer A, Schwenkert I, Dürrbeck H, Buchner S, Dabauvalle MC, Schmidt M, Qin G, Wichmann C, Kittel R, Sigrist SJ, Buchner E (2006) Bruchpilot, a protein with homology to ELKS/ CAST, is required for structural integrity and function of synaptic active zones in Drosophila. Neuron 49:833-844. CrossRef Medline

Wegerhoff R (1999) GABA and serotonin immunoreactivity during postembryonic brain development in the beetle Tenebrio molitor. Microsc Res Tech 45:154-164. CrossRef Medline

Weissbourd B, Ren J, DeLoach KE, Guenthner CJ, Miyamichi K, Luo L (2014) Presynaptic partners of dorsal raphe serotonergic and GABAergic neurons. Neuron 83:645-662. CrossRef Medline

Wilson RI (2013) Early olfactory processing in Drosophila: mechanisms and principles. Annu Rev Neurosci 36:217-241. CrossRef Medline

Wylie CJ, Hendricks TJ, Zhang B, Wang L, Lu P, Leahy P, Fox S, Maeno H, Deneris ES (2010) Distinct transcriptomes define rostral and caudal serotonin neurons. J Neurosci 30:670-684. CrossRef Medline

Yaksi E, Wilson RI (2010) Electrical coupling between olfactory glomeruli. Neuron 67:1034-1047. CrossRef Medline

Zhang B, Freeman MR, Waddell S (2010) Drosophila neurobiology: a laboratory manual. Cold Spring Harbor, NY: Cold Spring Harbor Laboratory.

Zhang X, Gaudry Q (2016) Functional integration of a serotonergic neuron in the Drosophila antennal lobe. eLife 5:e16836. CrossRef Medline

Zhang YQ, Rodesch CK, Broadie K (2002) Living synaptic vesicle marker: synaptotagmin-GFP. Genesis 34:142-145. CrossRef Medline 